\title{
Modeling and Optimization of Multi-Functional Ammonia Slip Catalysts for Diesel Exhaust Aftertreatment
}

Torp, Thomas Klint; Hansen, Brian Brun; Vennestrøm, Peter N. R.; Janssens, Ton V.W.; Jensen, Anker Degn

Published in:

Emission Control Science and Technology

Link to article, DOI:

$10.1007 / s 40825-020-00183-x$

Publication date:

2021

Document Version

Peer reviewed version

Link back to DTU Orbit

Citation (APA):

Torp, T. K., Hansen, B. B., Vennestrøm, P. N. R., Janssens, T. V. W., \& Jensen, A. D. (2021). Modeling and Optimization of Multi-Functional Ammonia Slip Catalysts for Diesel Exhaust Aftertreatment. Emission Control Science and Technology, 7, 7-25. https://doi.org/10.1007/s40825-020-00183-x

\section{General rights}

Copyright and moral rights for the publications made accessible in the public portal are retained by the authors and/or other copyright owners and it is a condition of accessing publications that users recognise and abide by the legal requirements associated with these rights.

- Users may download and print one copy of any publication from the public portal for the purpose of private study or research.

- You may not further distribute the material or use it for any profit-making activity or commercial gain

- You may freely distribute the URL identifying the publication in the public portal 


\title{
Modeling and Optimization of Multi-Functional Ammonia Slip Catalysts for Diesel Exhaust Aftertreatment
}

\author{
Thomas Klint Torp ${ }^{\mathrm{a}, \mathrm{b}}$, Brian Brun Hansen ${ }^{\mathrm{b}}$, Peter N.R. Vennestrømc, Ton V.W. Janssens ${ }^{\mathrm{c}}$, \\ and Anker Degn Jensen ${ }^{b^{*}}$ \\ ${ }^{a}$ Haldor Topsoe A/S, Haldor Topsøe Allé 1, 2800 Kgs. Lyngby, Denmark \\ ${ }^{b}$ Department of Chemical and Biochemical Engineering, Technical University of Denmark, Søltofts \\ Plads 229, 2800 Kgs. Lyngby, Denmark
}

c Umicore Denmark A/S, Kogle Alle 1, 2970 Hørsholm, Denmark

*Correspondence to aj@kt.dtu.dk

\begin{abstract}
Ammonia slip catalysts (ASC) are used downstream of the $\mathrm{NH}_{3}$-selective catalytic $\mathrm{NO}_{x}$ reduction (SCR) system, to minimize ammonia slip from transport sector SCR units. The ASC may consist of an SCR active layer for $\mathrm{NO}_{x}$ control, a layer with oxidation functionality for ammonia conversion, or a combination thereof, either as individual layers or as a single mixed layer. Mathematical models of such systems involve flow and mass transfer in the monolithic channels as well as coupled reaction/diffusion processes in the catalytic layers. In this work, we develop a single channel 1D-1D (pseudo 2D) steady-state tank-in-series mathematical model for monolithic ammonia slip catalysts with up to two layers. Kinetics of relevant reactions over the Cu-Beta zeolite and the $\mathrm{Pt} / \mathrm{TiO}_{2}$ layer, including SCR, ammonia oxidation and the formation of $\mathrm{N}_{2} \mathrm{O}$, were derived based on an extensive flow reactor study. The model was validated based on experiments using four different small-scale ASC monoliths, showing good agreement between the model predictions and the experimental results.

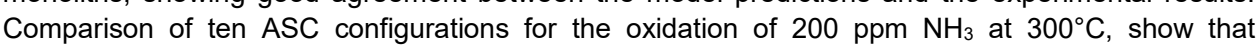
configurations with a pure layer of $\mathrm{NH}_{3}$ oxidation catalyst, generate undesirable high $\mathrm{N}_{2} \mathrm{O}$ and $\mathrm{NO}_{x}$ levels. The best ASC configurations feature fast diffusion in the catalytic layers (a high effective diffusion coefficient), a thin top layer loading with some ammonia oxidation catalyst, and a mixed layer of ammonia oxidation catalyst and the SCR catalyst to limit the formation of $\mathrm{N}_{2} \mathrm{O}$ and $\mathrm{NO}_{x}$.
\end{abstract}

\section{Keywords}

Ammonia Slip Catalyst, SCR, Ammonia Oxidation, Modeling, Diesel Exhaust Aftertreatment, Multiobjective Optimization

\section{Acknowledgements}

The financial support from Innovation Fund Denmark under Grant Number 103-2012-3 is gratefully acknowledged. 


\section{Introduction}

Nitrogen oxides $\left(\mathrm{NO}_{x}\right)$ are harmful for human health and the environment, and therefore, the emission of $\mathrm{NO}_{x}$ from diesel engines is strictly regulated in many places [1-3]. To mitigate $\mathrm{NO}_{x}$ emissions from diesel engines, the exhaust aftertreatment system contains a catalyst to convert $\mathrm{NO}_{x}$ to nitrogen and water. This conversion is based on the selective catalytic reduction (SCR) by $\mathrm{NH}_{3}$, and urea is added to the exhaust gas as a source of $\mathrm{NH}_{3}$ [3]. In practice, a small excess of urea is used to improve the $\mathrm{NO}_{x}$ reduction, but this also results in a slip of $\mathrm{NH}_{3}$ from the SCR catalyst [4]. Therefore, an ammonia slip catalyst (ASC) is placed immediately after the SCR catalyst, to limit unwanted emissions of $\mathrm{NH}_{3}$.

Ideally, an ammonia slip catalyst oxidizes the $\mathrm{NH}_{3}$ with $\mathrm{O}_{2}$ to nitrogen and water. These catalysts are usually based on supported Pt particles, which are very active for the oxidation of $\mathrm{NH}_{3}$ by $\mathrm{O}_{2}$, already at around $200^{\circ} \mathrm{C}[3,5,6]$. However, at higher temperatures, Pt based catalysts are not very selective for $\mathrm{N}_{2}$, and produce considerable amounts of $\mathrm{N}_{2} \mathrm{O}$ between $225-300^{\circ} \mathrm{C}$, and $\mathrm{NO}_{x}$ at temperatures above $250^{\circ} \mathrm{C}[3,6-14]$. The formation of $\mathrm{NO}_{x}$ and $\mathrm{N}_{2} \mathrm{O}$ in an ASC is counterproductive for abatement of $\mathrm{NO}_{x}$. Furthermore, the formation of $\mathrm{N}_{2} \mathrm{O}$ is problematic since $\mathrm{N}_{2} \mathrm{O}$ is a strong greenhouse gas, about 300 times more potent than $\mathrm{CO}_{2}$ [3], and emissions of $\mathrm{N}_{2} \mathrm{O}$ are likely to be restricted in future emission regulations as well.

To improve the selectivity for $\mathrm{N}_{2}$, an ASC usually consists of an ammonia oxidation (AMOX) catalyst component, often based on Pt, combined with an SCR catalyst [3, 6-15]. The SCR catalyst effectively converts the $\mathrm{NO}_{x}$ produced from oxidation of $\mathrm{NH}_{3}$ to $\mathrm{N}_{2}$, as long as $\mathrm{NH}_{3}$ is present, via the $\mathrm{NH}_{3}-\mathrm{SCR}$ reactions. There are several ways to combine the AMOX component with an SCR catalyst, leading to different configurations of the ASC. The simplest way is to mix the SCR catalyst with the AMOX catalyst $[8,10-12,14,15]$. Often, however, the SCR catalyst is applied as a separate layer on top of the AMOX catalyst, creating a dual layer structure $[3,6-12,14,16]$, or as a hybrid consisting of a mixed bottom layer with an SCR top layer [10,14]. In general, adding an SCR component to the ASC improves the $\mathrm{N}_{2}$ selectivity compared to that of a Pt based AMOX catalyst alone.

The SCR catalyst that is used in an ASC must be very active for SCR, in order to obtain sufficient $\mathrm{N}_{2}$ selectivity. Therefore, $\mathrm{Cu}$ - or Fe-zeolites are used in ASC, because these are the most active catalysts available for SCR. Mathematical modeling and experimental studies of $\mathrm{ASC}$ with $\mathrm{Pt} / \mathrm{Al}_{2} \mathrm{O}_{3}$ and $\mathrm{Cu}$ - or Fe-zeolite components have demonstrated a number of advantages and disadvantages of the different designs of the ASC $[5-7,10-12,14,15,17,18]$. In general, there is a trade-off between $\mathrm{NH}_{3}$ conversion and $\mathrm{N}_{2}$ selectivity. A single mixed layer design provides the highest accessibility of the gas species to the AMOX catalyst, leading to a higher $\mathrm{NH}_{3}$ conversion, but also a lower selectivity for $\mathrm{N}_{2}$, albeit with the advantage of a lower $\mathrm{N}_{2} \mathrm{O}$ selectivity, as compared to a Pt catalyst only $[8,10-12,14$, 15]. A dual layer design with an SCR catalyst on top of the AMOX catalyst enhances the $\mathrm{N}_{2}$ selectivity, but lowers the $\mathrm{NH}_{3}$ conversion, since the SCR catalyst layer introduces a mass transfer resistance to the AMOX catalyst $[8,10-12,14,15]$. The mass transfer can be improved by adding starch to the washcoat formulation, which after calcination leaves additional porosity [16]. A hybrid configuration consisting of an SCR top layer and a mixed bottom layer leads to an intermediate $\mathrm{NH}_{3}$ conversion and product selectivity $[8,10-12,14,15]$.

Most studies that compare the performance of different configurations for the ASC $[5-12,14,15,17$, $19,20]$ are limited to combinations of given amounts of AMOX and SCR components, which are then distributed in different ways according to preselected catalyst configurations. In some studies, the basic configuration is kept constant and the amount of a catalyst component is varied, for example, the amount of $\mathrm{Pt}$ catalyst in the mixed layer in a hybrid catalyst design (top Cu/SSZ-13, base $\mathrm{Pt} / \mathrm{Al}_{2} \mathrm{O}_{3}$ 
+ Cu/SSZ-13) [14]. However, the optimal performance of an ASC depends both on the amounts of SCR and AMOX components, and on the configuration of the catalyst. A non-optimal formulation will not reveal the full potential of a given ASC configuration, and consequently, a comparison of catalysts with different formulations can lead to misleading conclusions, if the possible effects of the configuration are ignored.

The optimization of an ASC is a multi-objective optimization problem, due to the trade-offs between $\mathrm{NH}_{3}$ conversion and product selectivity. This means that an optimal ASC design also depends on the requirements for a specific application. For example, in some cases it could be advantageous to focus on low $\mathrm{NO}_{x}$ or $\mathrm{N}_{2} \mathrm{O}$ formation in the ASC, rather than maximizing $\mathrm{NH}_{3}$ conversion, or a high SCR activity in order to effectively extend the upstream SCR unit. Combined, these considerations make it difficult to draw general conclusions on the advantages and disadvantages of the different ASC designs, and they must instead be evaluated case-by-case.

To be able to select a good configuration of an ASC, a good understanding of the interplay of the amounts of the AMOX and SCR catalyst components and the design of the catalyst is necessary. It is therefore desirable to have a model that can translate the process requirements into a suitable configuration of an ASC and guide the development process. In this work, we derive a mathematical model for a single channel of a monolithic ASC and use it to evaluate ten different ammonia slip catalyst configurations through multi-objective optimization. The kinetics of the relevant reactions over Pt-based AMOX and SCR catalyst components, including $\mathrm{N}_{2} \mathrm{O}$ formation, are determined based on extensive flow reactor experiments. Furthermore, we use $\mathrm{NH}_{3}$ oxidation at an intermediate operating temperature of $300^{\circ} \mathrm{C}$, relevant for many test cycles, for the evaluation of different catalyst configurations. For each configuration, we consider the amounts of AMOX or SCR catalyst in each layer, the effective diffusion coefficient in the catalyst layers, which is affected by the average pore diameter in the layers, and the intrinsic activity of the AMOX catalyst, which depends on the Pt content in the AMOX catalyst that is added. The optimization results form a set of optimal solutions (Pareto set), which are visualized by Pareto fronts generated for optimization of an ASC configuration. These data are then used to compare and evaluate the potential of different catalyst configurations and formulations. The multi-objective optimization also gives an indication of the sensitivity of the ASC performance to catalyst architecture and is an example of how an optimal ASC can be designed.

\section{Experimental}

\subsection{Catalyst Preparation}

\subsubsection{Powder Catalysts}

The monolithic ASC samples studied in this work were based on the combination of a $1 \mathrm{wt} . \% \mathrm{Pt}$ on $\mathrm{TiO}_{2}$ support as the AMOX catalyst, and a $3.5 \mathrm{wt}$ \% Cu-Beta SCR catalyst. The $1 \mathrm{wt} . \% \mathrm{Pt} / \mathrm{TiO} \mathrm{AMOX}_{2}$ catalyst was prepared by impregnation of the support material with $\mathrm{Pt}\left(\mathrm{NH}_{3}\right)_{4}\left(\mathrm{HCO}_{3}\right)_{2}$ followed by drying at $100^{\circ} \mathrm{C}$, and calcination at $550^{\circ} \mathrm{C}$ in air for 2 hours. The $3.5 \mathrm{wt} . \%$ Cu-Beta SCR catalyst was prepared by impregnation of the parent Beta zeolite $(\mathrm{Si} / \mathrm{Al}=20)$ with $\mathrm{Cu}\left(\mathrm{NO}_{3}\right)_{2} \cdot 3 \mathrm{H}_{2} \mathrm{O}$, followed by drying at $115^{\circ} \mathrm{C}$ and calcination in air at $550^{\circ} \mathrm{C}$. The catalysts were tableted, crushed, and sieved to a fraction of either $106-150 \mu \mathrm{m}$ or $150-300 \mu \mathrm{m}$ prior to activity measurements using fixed bed reactors.

\subsubsection{Monolith Catalysts}

Four monolithic ammonia slip catalysts with different configurations were prepared: single layer AMOX, single layer SCR, single mixed layer, and dual layer with the SCR catalyst on top of the AMOX 
catalyst layer. The catalysts were prepared by dip coating square channel cordierite monolith substrates with $300 \mathrm{cpsi}$ in slurries of $1 \mathrm{wt} \% \mathrm{Pt} / \mathrm{TiO}_{2}$ (AMOX catalyst) and/or $3.5 \mathrm{wt}$ \% Cu-Beta (SCR catalyst). The aqueous slurries consisted of the respective catalysts and a colloidal silica binder. The slurries were milled to break agglomerates and obtain small catalyst particles with an average catalyst particle size of $3 \mu \mathrm{m}$ for the AMOX catalyst and $18 \mu \mathrm{m}$ for the SCR catalyst.

For the SCR catalyst slurry applied to the single layer SCR and the dual layer sample, an aqueous solution of an organic stabilizer (xanthan gum) was added after milling. In order to control the catalyst loading applied by dip coating, the dry matter content was adjusted by adding demineralized water.

In the case of the AMOX catalyst slurry for single layer AMOX and the dual layer sample, Pt-free $\mathrm{TiO}_{2}$ support material was added in order to dilute the Pt content from $1 \mathrm{wt} . \%$ to $0.25 \mathrm{wt} . \%$. The Pt content of a calcined sample of the AMOX catalyst slurry was $0.235 \mathrm{wt} . \% \mathrm{Pt}$, as determined by inductively coupled plasma optical emission spectrometry. An aqueous $\mathrm{NH}_{3}$ solution (30-33 wt.\% $\mathrm{NH}_{3}$ ) was used to regulate the $\mathrm{pH}$ of the washcoat slurry to $9-10$.

To avoid differences in the AMOX catalyst loading for the single layer AMOX and dual layer sample, a large monolith substrate $(d 0.266 \mathrm{~m} \times L 0.152 \mathrm{~m})$ with 300 cells per square inch and 6 mil $(152 \mu \mathrm{m})$ thick channel walls was initially coated with the AMOX washcoat slurry by dip coating. The excess slurry was removed by blowing a stream of air through the channels using an air knife. The coated monolith substrate was then dried overnight at room temperature, with a flow of air through the channels, followed by further drying overnight in an oven at $80^{\circ} \mathrm{C}$, and the dried AMOX catalyst coated monolith was cut into smaller samples $(d 0.05 \mathrm{~m} \times L 0.037 \mathrm{~m})$. To prepare the dual layer sample, one of these samples coated with AMOX catalyst was dip coated with SCR washcoat slurry.

The single layer Cu-Beta SCR sample was prepared by dip coating a small ( $d 0.05 \mathrm{~m} \times L 0.037 \mathrm{~m}$ ) sample of uncoated cordierite monolith substrate of the same type used for the initial AMOX catalyst washcoating. The single mixed layer catalyst was prepared using a similar procedure, but using a slurry containing a mixture of the AMOX and SCR catalysts.

After dip coating and removal of excess slurry, the small monolithic catalyst samples were dried at room temperature with a flow of air through the channels for 30 minutes. The monolithic catalyst samples were calcined at $550^{\circ} \mathrm{C}$ for 2 hours. An overview of the prepared catalysts is presented in Table 1.

\subsection{Activity Measurements}

\subsubsection{Fixed Bed Reactor}

The catalytic activity of the AMOX and SCR catalysts were evaluated using two different fixed bed reactor setups.

For the AMOX catalyst, the fixed bed reactor setup used a quartz U-tube reactor $\left(d_{i}=2 \mathrm{~mm}\right)$ loaded with $5 \mathrm{mg}$ of the $1 \mathrm{wt} . \% \mathrm{Pt} / \mathrm{TiO}_{2}$ catalyst $(150-300 \mu \mathrm{m})$, fixed between two plugs of quartz wool. A thermocouple was placed at the position of the catalyst bed on the outside of the reactor giving a temperature representative of the average catalyst temperature. The feed gas consisted of $500 \mathrm{ppm}$ $\mathrm{NH}_{3}, 5$ vol. $\% \mathrm{H}_{2} \mathrm{O}, 10$ vol. $\% \mathrm{O}_{2}$, and balance $\mathrm{N}_{2}$, with a total flow of $400 \mathrm{NmL} / \mathrm{min}$. An FTIR gas analyzer (Gasmet; CX4000) measured the concentrations of $\mathrm{NH}_{3}, \mathrm{NO}, \mathrm{NO}_{2}, \mathrm{~N}_{2} \mathrm{O}$, and $\mathrm{H}_{2} \mathrm{O}$ in the outlet gas. The $\mathrm{N}_{2}$ concentration was calculated from the $\mathrm{N}$-balance. The catalyst was heated to $550^{\circ} \mathrm{C}$ at a rate of $20^{\circ} \mathrm{C} / \mathrm{min}$ in the feed gas and held at these conditions for 1 hour. Afterwards, the catalyst was 
stepwise cooled to $200^{\circ} \mathrm{C}$, with smaller steps taken for temperatures below $300^{\circ} \mathrm{C}$. Steady-state measurements were made at each temperature for a duration of 20 minutes.

A second fixed bed reactor setup was used for the catalytic activity measurements of the $3.5 \mathrm{wt} . \% \mathrm{Cu}-$ Beta SCR catalyst. A quartz U-tube reactor $\left(d_{i}=6 \mathrm{~mm}\right)$ was loaded with a mixture of $20 \mathrm{mg}$ catalyst $(106-150 \mu \mathrm{m})$ and $100 \mathrm{mg} \mathrm{SiC}(150-300 \mu \mathrm{m})$, fixed between two plugs of quartz wool. For measurements made below $225^{\circ} \mathrm{C}$, a sample of $40 \mathrm{mg}$ catalyst and $200 \mathrm{mg} \mathrm{SiC}$ was used instead to obtain sufficient conversion. The gas flowed upwards through the catalyst bed and the temperature was measured with a thermocouple placed inside the reactor at the catalyst bed outlet. The base of the feed gas consisted of 5 vol. $\% \mathrm{H}_{2} \mathrm{O}, 10$ vol. $\% \mathrm{O}_{2}$, and balance $\mathrm{N}_{2}$, with a total flow of $1000 \mathrm{NmL} / \mathrm{min}$. Water was added to the gas mixture by bubbling a separate flow of $\mathrm{N}_{2}$ through water heated to $80^{\circ} \mathrm{C}$. Concentrations of approximately $600 \mathrm{ppm} \mathrm{NH}$ and $500 \mathrm{ppm} \mathrm{NO}$ were used to give an $\mathrm{NH}_{3}$-to- $\mathrm{NO}_{x}$ molar ratio of 1.2. The $\mathrm{NO}_{2} / \mathrm{NO}_{x}$ ratio in the feed was varied between $0,0.5$, or 1 . The investigation of catalytic activity was performed by initially heating the catalyst to $550^{\circ} \mathrm{C}$ in a standard SCR mixture for 1 hour followed by cooling to $150^{\circ} \mathrm{C}$ in the same gas mixture. The catalyst was then stepwise heated to the selected temperatures, and the composition of the reactor exit gas was measured for a duration of 1 hour at each temperature, with feed gas measurements made both before and after. The composition of the reactor exit gases was measured using several methods. The concentrations of $\mathrm{NH}_{3}, \mathrm{NO}$, and $\mathrm{NO}_{2}$ were measured using a continuous gas analyzer (Limas11-HW; ABB) and the concentration of $\mathrm{H}_{2} \mathrm{O}$ was determined using a humidity probe (HC2-IC102; Rotronic). After the gas analyzer, $\mathrm{H}_{2} \mathrm{O}$ was condensed from the gas and the concentration of $\mathrm{N}_{2} \mathrm{O}$ in the resulting gas was measured using a micro-GC (Varian; CP-490), and corrected for the concentration of water removed. The $\mathrm{N}_{2}$ concentration was calculated from the $\mathrm{N}$-balance.

\subsubsection{Monolith Flow Reactor}

The monolith catalysts were tested for $\mathrm{NH}_{3}$ oxidation in a flow reactor designed for testing small monolith samples $(d 0.05 \mathrm{~m} \times L 0.037 \mathrm{~m})$. Prior to loading the monolithic catalyst, a small hole was drilled in the middle of the outlet end of the monolith, in order to accommodate the thermocouple placed in the center of the sample giving a temperature representative of the average catalyst temperature. The monolith sample was then loaded into a steel reactor tube, with a gas mixing block placed directly upstream. The base of the feed gas was made by mixing flows of air, $\mathrm{N}_{2}$, and $\mathrm{H}_{2} \mathrm{O}$. The gas flow was directed through a pre-heater to heat the gas to the selected temperature of the reactor. $\mathrm{NH}_{3}$ was added to the feed gas immediately before the mixing block. The feed gas used in this study consisted of $200 \mathrm{ppm} \mathrm{NH}, 4$ vol. $\% \mathrm{H}_{2} \mathrm{O}, 12 \mathrm{vol} . \% \mathrm{O}_{2}$, in $\mathrm{N}_{2}$, at a total flow of $18,200 \mathrm{NL} / \mathrm{hr}$. This corresponds to gas hourly space velocity (GHSV) of $250,000 \mathrm{hr}^{-1}$, based on the total gas flow and the total volume of the monolith catalyst sample. Shortly downstream of the catalyst, an FTIR gas analyzer (Gasmet; CX4000) was used to measure the concentration of $\mathrm{NH}_{3}, \mathrm{NO}, \mathrm{NO}_{2}, \mathrm{~N}_{2} \mathrm{O}$, and $\mathrm{H}_{2} \mathrm{O}$. The catalyst sample was initially heated to $550^{\circ} \mathrm{C}$ in the feed gas and held at these conditions for 1 hour, and then subsequently cooled to $170^{\circ} \mathrm{C}$ The feed gas concentration was measured at a reactor temperature of $170^{\circ} \mathrm{C}$; at this temperature the ASC is not active. Steady-state measurements were made afterwards by stepwise heating the catalyst to selected temperatures between 200 and $550^{\circ} \mathrm{C}$. 


\section{Mathematical Models and Multi-Objective Optimization}

\subsection{Monolith Model}

A model was developed to describe the monolithic ASC containing two layers. Each of the two layers in the model contains either an SCR functionality, an AMOX functionality or a combination of both, see Figure 1. The model was used to evaluate ten different configurations as illustrated in Figure 2.

The monolith reactor model is based on a single channel of a monolithic ASC. We have used a tankin-series approach to simulate the flow in the channel, assuming isothermal, isobaric, and steady-state conditions. For each tank in the model, the mass balance is solved, considering the convective gas flow in and out of the tank, as well as the mass transfer to the surface of the catalyst washcoat. The mass balance then becomes:

$$
Q \cdot\left(C_{g, i, k-1}-C_{g, i, k}\right)=k_{m t, i} \cdot A_{S} \cdot\left(C_{g, i, k}-C_{s, i, k}\right)
$$

The mass transfer coefficient is calculated using bulk diffusion coefficients for $\mathrm{NH}_{3}, \mathrm{NO}, \mathrm{NO}_{2}$, and $\mathrm{N}_{2} \mathrm{O}$ from temperature dependent expressions readily available in the literature for studies of similar catalyst systems [21], and are summarized in Table 2.

$$
k_{m t, i}=\frac{D_{b u l k, i} \cdot S h_{i}}{d_{H}}
$$

The position dependent Sherwood number was calculated using the following correlation for square channels $[9,22]$ :

$$
\begin{gathered}
S h_{i}=2.98+8.827\left(1000 \cdot z_{i}\right)^{-0.545} \exp \left(-48.2 \cdot z_{i}\right) \\
z_{i}=\frac{x \cdot D_{b u l k, i}}{u_{x} \cdot d_{H}^{2}}
\end{gathered}
$$

For each tank considered, the intrapore diffusion and reaction of $\mathrm{NH}_{3}, \mathrm{NO}, \mathrm{NO}_{2}$, and $\mathrm{N}_{2} \mathrm{O}$ throughout the catalyst washcoat phase was modeled, assuming the AMOX/SCR contributions to the reaction rate are proportional to their volumetric fractions:

$$
D_{e f f, i} \frac{d^{2} C_{w c, i}}{d r^{2}}+\sum_{c a t}^{A M O X, S C R}\left(\phi_{c a t} \cdot \rho_{c a t} \cdot R_{c a t, i}^{\prime}\right)=0
$$


To calculate the concentration profiles through the washcoat layer at a given location in the monolith, we introduce the following boundary conditions for the washcoat layer. At the surface of the top washcoat layer ( $t /$ ), the steady-state assumption entails that the mass transfer across the gas film is equal to the flux of mass into the washcoat phase (eq. 6). At the interface between the bottom layer/washcoat $(b /)$ and the monolith wall, no concentration gradient is present (eq. 7 ):

$$
\begin{gathered}
\left.D_{e f f, t l, i} \frac{d C_{w c, i}}{d r}\right|_{g / t l}=k_{m t, i} \cdot A_{S}\left(C_{g, i, k}-C_{s, i, k}\right) \\
\left.\frac{d C_{w c, i}}{d r}\right|_{w c / w a l l}=0
\end{gathered}
$$

For cases where there are two catalyst layers with different diffusivity, one needs to specify the boundary conditions at the interface between the layers as well. The first boundary condition given by equation 8 states that the flux of a species diffusing out of the top layer is equal to the flux of a species diffusing into the bottom layer.

$$
\left.D_{e f f, t l, i} \frac{d C_{w c, i}}{d r}\right|_{t l, \text { interface }}=\left.D_{e f f, b l, i} \frac{d C_{w c, i}}{d r}\right|_{\text {bl,interface }}
$$

The second boundary condition for the interface is an equation of continuity for the different species at the interface.

$$
\left.C_{w c, i}\right|_{t l, \text { interface }}=\left.C_{w c, i}\right|_{\text {bl,interface }}
$$

The effective diffusion coefficient in the catalyst washcoat phase, $D_{e f f}$, is calculated using the mean transport pore model [23], which accounts for contributions from both bulk and Knudsen diffusion. The mean transport pore model was chosen over more complex models, such as the random pore model, to limit model complexity [14, 23-25].

$$
D_{\text {eff }, i}=\frac{\epsilon}{\tau} \cdot\left(\frac{1}{D_{b u l k, i}}+\frac{1}{D_{K, i}}\right)^{-1}
$$

The values of the porosity, $\epsilon$, and tortuosity, $\tau$, are set to 0.4 and 3 , respectively, which are common and realistic values [26]. As previously mentioned, the bulk diffusion coefficients, $D_{\text {bulk, }, \text {, for }} \mathrm{NH}_{3}, \mathrm{NO}$, $\mathrm{NO}_{2}$, and $\mathrm{N}_{2} \mathrm{O}$ were calculated using the expressions in Table 2 [21]. The Knudsen diffusion coefficient, $D_{K, i}$, was calculated using equation 11 [23]: 


$$
D_{K, i}=\frac{d_{\text {pore }}}{3} \sqrt{\frac{8 \cdot R \cdot T}{M_{w, i} \cdot \pi}}
$$

The values for the average pore diameters, $d_{\text {pore }}$, were estimated by fitting the model against the experimental data for the monolithic ASC samples.

The monolith model was implemented in MATLAB and the bvp4c function was used to solve the boundary value problem of the monolith wall. For 10 tanks or more, the difference between solutions resulting from a change in the number of tanks was negligible, and therefore, we chose to use 10 tanks for our simulations. For the washcoat layer, a step size of $0.5 \mu \mathrm{m}$ was used in the discretization.

\subsection{Kinetic Models}

In order to calculate the concentration profiles in the monolith reactor, the reaction rates in the washcoat layer must be known (see eq. 5). These reaction rates are derived from kinetic models for the $1 \mathrm{wt} . \% \mathrm{Pt} / \mathrm{TiO}_{2} \mathrm{AMOX}$ catalyst and the $3.5 \mathrm{wt} . \% \mathrm{Cu}$-Beta SCR catalyst. These models were developed based on activity measurements from fixed bed reactors and a reactor model for the fixed bed reactor. We used the Isqcurvefit function in MATLAB to fit the pre-exponential factor and the activation energy $\left(A_{j}, E_{A, j}\right)$. The objective function was set to minimize the difference between simulated and experimental outlet concentrations of the reactants and products $\left(i=\mathrm{NH}_{3}, \mathrm{NO}, \mathrm{NO}_{2}, \mathrm{~N}_{2} \mathrm{O}\right.$, and $\left.\mathrm{N}_{2}\right)$, as given by equation 12 :

$$
\min _{A_{j}, E_{A, j}}=\sum_{i}\left(y\left(A_{j}, E_{A, j}\right)_{s i m, i}-y_{\text {exp }, i}\right)^{2}
$$

For the fixed bed reactor, we assumed ideal plug flow, steady-state, isothermal, and isobaric conditions. Equation 13 describes the fixed bed reactor material balance in terms of the gas phase concentration:

$$
Q \cdot \frac{d C_{g, i}}{d W}=R_{c a t, i}^{\prime}
$$

The material balance for the adsorbed phase is simplified by the steady-state conditions:

$$
\Omega_{i} \frac{d \theta_{i}}{d t}=0
$$

The catalytic mass based rate of reaction for each reactant $i$ is expressed by equation 15 and the reaction rate coefficient from the Arrhenius expression (equation 16). During fitting of the kinetic 
parameters, a reformulation of equation 16 was used to decouple $A_{j}$ and $E_{A, j}$ [27]. For conversion from mass to volume based reaction rates, the following catalyst densities are used $\rho_{\text {AMOX }}=1127 \mathrm{~kg}$ cat $/ \mathrm{m}^{3}$ and $\rho_{S C R}=954 \mathrm{~kg}$ cat $/ \mathrm{m}^{3}$.

$$
\begin{aligned}
R_{c a t, i}^{\prime} & =\sum_{j=1}^{N_{r}} v_{i, j} \cdot r_{j}^{\prime}\left(p_{i}, \theta_{i}, k_{j}\right) \\
k_{j} & =A_{j} \exp \left(-\frac{E_{A, j}}{R \cdot T}\right)
\end{aligned}
$$

\subsubsection{Kinetic Model for the Ammonia Oxidation Catalyst}

In this paper we are interested in a simple kinetic models giving a good representation of the overall reactions, and not a full micro-kinetic model. First, we establish a simple kinetic model for $\mathrm{NH}_{3}$ oxidation catalyzed by the $1 \mathrm{wt} . \% \mathrm{Pt} / \mathrm{TiO}_{2}$ to describe the oxidation of $\mathrm{NH}_{3}$ over the AMOX catalyst. The relevant reactions for this model are summarized in Table 3. These include the adsorption and desorption of $\mathrm{NH}_{3}$ on the catalyst surface (AMOX.1), the oxidation of adsorbed $\mathrm{NH}_{3}$ to $\mathrm{N}_{2}$ (AMOX.2) and $\mathrm{NO}$ (AMOX.3), the oxidation of $\mathrm{NH}_{3}$ and $\mathrm{NO}$ to $\mathrm{N}_{2} \mathrm{O}$ (AMOX.4) $[5,8,12,28]$ and the oxidation of $\mathrm{NO}$ to $\mathrm{NO}_{2}$ (AMOX.5f). The oxidation of $\mathrm{NO}$ is a reversible reaction and the reverse reaction is included as the decomposition of $\mathrm{NO}_{2}$ (AMOX.5b) $[11,12,21]$. The equilibrium constant for this reaction was calculated from thermodynamic data [29] to ensure thermodynamic consistency.

Under typical reaction conditions, the amounts of $\mathrm{H}_{2} \mathrm{O}$ and $\mathrm{O}_{2}$ are much larger than those of the key reactants and products $\left(\mathrm{NH}_{3}, \mathrm{NO}, \mathrm{NO}_{2}\right.$, and $\left.\mathrm{N}_{2} \mathrm{O}\right)$. Therefore, the concentrations of $\mathrm{H}_{2} \mathrm{O}(5 \mathrm{vol}$. \%) and $\mathrm{O}_{2}$ (10 vol. \%) have been kept constant and do not appear explicitly in the rate equations. The only exception is the rate expression for $\mathrm{NO}$ oxidation and $\mathrm{NO}_{2}$ decomposition (AMOX.5f), where the $\mathrm{O}_{2}$ concentration is included.

\subsubsection{Kinetic Model for the Selective Catalytic Reduction}

To describe the SCR reaction over the $3.5 \mathrm{wt}$.\% Cu-Beta catalyst, we adopted the kinetic model for $\mathrm{Cu}-\mathrm{CHA}$ proposed by Metkar et al. [21]. The reactions and associated rate expressions are listed in Table 4. The reactions include $\mathrm{NH}_{3}$ adsorption and desorption on the catalyst (SCR.1), $\mathrm{NH}_{3}$ oxidation (SCR.2), NO oxidation (SCR.3f), and $\mathrm{NO}_{2}$ decomposition (SCR.3b). In contrast to the Pt-based AMOX catalyst, the $\mathrm{NH}_{3}$ oxidation reaction on Cu-Beta primarily leads to the formation of $\mathrm{N}_{2}$, with $\mathrm{NO}$ and $\mathrm{N}_{2} \mathrm{O}$ being formed in rather insignificant quantities $[10,21,30]$. Therefore, we only consider $\mathrm{N}_{2}$ as the product of $\mathrm{NH}_{3}$ oxidation. The oxidation of $\mathrm{NO}$ and the decomposition of $\mathrm{NO}_{2}$ was handled in the same manner as for the AMOX catalyst, using the thermodynamic equilibrium [29]. The SCR reactions included in the model are: standard (SCR.4), slow (SCR.6), and fast (SCR.8).

A difference between the Cu-Beta and $\mathrm{Cu}-\mathrm{CHA}$ catalyst is that a Cu-Beta catalyst has a higher selectivity for the formation of $\mathrm{N}_{2} \mathrm{O}$. Formation of $\mathrm{N}_{2} \mathrm{O}$ has been attributed to the decomposition of an $\mathrm{NH}_{4} \mathrm{NO}_{3}$ intermediate, which forms from reaction of $\mathrm{NH}_{3}$ and $\mathrm{NO}_{2}[21,30]$ :

$$
4 \mathrm{NH}_{3}+4 \mathrm{NO}_{2} \rightarrow 2\left[\mathrm{NH}_{4} \mathrm{NO}_{3}\right]+2 \mathrm{~N}_{2}+2 \mathrm{H}_{2} \mathrm{O} \rightarrow 2 \mathrm{~N}_{2} \mathrm{O}+2 \mathrm{~N}_{2}+6 \mathrm{H}_{2} \mathrm{O}
$$


The reaction between adsorbed $\mathrm{NH}_{3}$ and $\mathrm{NO}_{2}$ (SCR.7), based on reaction (R.1), accounts for the formation of $\mathrm{N}_{2} \mathrm{O}$ in the presence of $\mathrm{NO}_{2}$. However, $\mathrm{N}_{2} \mathrm{O}$ is also formed only in the presence of $\mathrm{NO}$. One possible explanation is found in the mechanism for the standard SCR reaction proposed by Janssens et al. [4], in which $\mathrm{NO}_{2}$ is formed in the catalytic cycle. Therefore, we also include a reaction between $\mathrm{NH}_{3}$ and $\mathrm{NO}$ (SCR.5), similar to reaction SCR.4, to account for $\mathrm{N}_{2} \mathrm{O}$ formation from a feed gas without $\mathrm{NO}_{2}$. These two reactions (SCR.5 and SCR.7) account for the majority of $\mathrm{N}_{2} \mathrm{O}$ formed during fast SCR conditions, but are not enough to account for all $\mathrm{N}_{2} \mathrm{O}$ formed. As a result, it was necessary to include an extra $\mathrm{N}_{2} \mathrm{O}$ contribution, due to an enhanced $\mathrm{N}_{2} \mathrm{O}$ formation in the presence of both $\mathrm{NO}$ and $\mathrm{NO}_{2}$ (SCR.9), similar to the improved rate of reaction during fast SCR conditions. By including the partial pressures of both $\mathrm{NO}$ and $\mathrm{NO}_{2}$ in the rate expression, it is ensured that the reaction is only considered under fast SCR conditions, even though it only consumes $\mathrm{NO}_{2}$.

With regard to the standard SCR reaction, it has been reported in the literature [31-34] that the NO conversion versus temperature over Cu-zeolites is atypical. The NO conversion increases with temperature as expected until about $225-250^{\circ} \mathrm{C}$, at which point the conversion decreases to a local minimum at about $350^{\circ} \mathrm{C}$, before increasing again [34]. This behavior corresponds to a gradual transition between a low temperature reaction route which peaks at $250^{\circ} \mathrm{C}$ and a high temperature reaction route that dominates at temperatures above $350^{\circ} \mathrm{C}$. At temperatures below $250^{\circ} \mathrm{C}$, isolated $\mathrm{Cu}$ sites cannot activate $\mathrm{O}_{2}$ independently, and two mobile $\left[\mathrm{Cu}^{\prime}\left(\mathrm{NH}_{3}\right)_{2}\right]^{+}$ions are needed, forming an $\left[\mathrm{Cu}^{\prime}\left(\mathrm{NH}_{3}\right)_{2}\right]^{+}-\mathrm{O}_{2}-\left[\mathrm{Cu}^{\prime}\left(\mathrm{NH}_{3}\right)_{2}\right]^{+}$intermediate [34-36]. When the temperature increases, the $\mathrm{Cu}$ ions are immobilized by desorption of the $\mathrm{NH}_{3}$ ligand, and the activation of $\mathrm{O}_{2}$ now occurs on isolated $\mathrm{Cu}^{\prime}$ sites, with an increased reaction barrier [34-36].

To account for this transition in the kinetic model, two sets of kinetic parameters for the standard SCR and corresponding $\mathrm{N}_{2} \mathrm{O}$ formation were included in the model; one set for each kinetic regime. To weigh the contribution of the low (mobile $\mathrm{Cu}$ sites) and high (immobilized $\mathrm{Cu}$ sites) temperature kinetics, a fractional weighting given by $x_{L T}$ and $x_{H T}=1-x_{L T}$ with values between 0 and 1 was applied. The balance and transfer between the kinetic regimes was modeled similar to a Langmuir adsorption equilibrium reaction (SCR.10), with an equilibrium constant expressed using the following version of the Van't Hoff equation:

$$
K_{e q, x}=\exp \left(\frac{-\Delta H+T \cdot \Delta S}{R \cdot T}\right)
$$

The values for the change in reaction enthalpy, $\Delta H$, and entropy, $\Delta S$, were estimated by a parameter fitting. The fractions of $x_{L T}$ and $x_{H T}$ are determined from the equilibrium constant and the relationship between $X_{L T}$ and $X_{H T}$ :

$$
\begin{gathered}
x_{L T}=\frac{1}{1+K_{e q, x}} \\
x_{H T}=1-x_{L T}
\end{gathered}
$$

Table 4 summarizes the reactions and rate expressions in our kinetic model for the $3.5 \mathrm{wt} . \%$ Cu-Beta SCR catalyst.

\subsection{Multi-Objective Optimization}

The design of an ASC is a multi-objective optimization problem since the goal is to minimize emissions of $\mathrm{NH}_{3}, \mathrm{NO}_{x}$, and $\mathrm{N}_{2} \mathrm{O}$, as well as the cost, size, and weight of the ASC. For simplicity, we here focus on minimizing emissions and disregard the other design objectives. Furthermore, we will consider an 
equal $\mathrm{N}$-based weighting for $\mathrm{NH}_{3}, \mathrm{NO}_{x}$, and $\mathrm{N}_{2} \mathrm{O}$ slip. An optimal set of values for the design parameters therefore results in the lowest total emissions of $\mathrm{NH}_{3}, \mathrm{NO}_{x}$, and $\mathrm{N}_{2} \mathrm{O}$. Due to the trade-off that occurs between $\mathrm{NH}_{3}$ conversion (equation 20) and the formation of either $\mathrm{N}_{2}$ or emissions of $\mathrm{NO}_{x}$ and $\mathrm{N}_{2} \mathrm{O}$ (equation 21-23) for the ASC, there exist many possible combinations of $\mathrm{NH}_{3}, \mathrm{NO}_{x}$, and $\mathrm{N}_{2} \mathrm{O}$ outlet concentrations that provide the lowest total emissions, all with their respective set of parameter values.

$$
\begin{aligned}
\mathrm{NH}_{3, \text { conv }} & =\frac{C_{g, \mathrm{NH} 3, \text { in }}-C_{g, \mathrm{NH} 3, \text { out }}}{C_{g, \mathrm{NH} 3, \text { in }}} \\
\mathrm{N}_{2} \mathrm{O}_{\text {selec }} & =\frac{2 \cdot C_{g, \mathrm{~N} 2 \mathrm{O}, \text { out }}}{C_{g, \mathrm{NH} 3, \text { in }}-C_{g, \mathrm{NH} 3, \text { out }}} \\
\mathrm{NO}_{x, \text { selec }} & =\frac{C_{g, \mathrm{NO}}, \text { out }}{C_{g, \mathrm{NH} 3, \text { in }}-C_{g, \mathrm{NH} 3, \text { out }}} \\
\mathrm{N}_{2, \text { selec }} & =1-\mathrm{N}_{2} \mathrm{O}_{\text {selec }}-\mathrm{NO}_{x, \text { selec }}
\end{aligned}
$$

This is common for multi-objective problems and the set of optimal solutions forms a front reflecting the trade-off known as a Pareto front. This concept is illustrated for the ASC in Figure 3, where the sum of $\mathrm{NO}_{x}$ and $\mathrm{N}_{2} \mathrm{O}$ slip is plotted against $\mathrm{NH}_{3}$ slip. The ideal solution occurs for $0 \mathrm{ppm} \mathrm{NH}_{3}$ slip and 0 ppm $\left(\mathrm{NO}_{x}+2 x \mathrm{~N}_{2} \mathrm{O}\right.$ slip), corresponding to $100 \% \mathrm{~N}_{2}$ yield (origin in green region). The optimal solutions are those closest to the ideal solution and they form the Pareto front (solid green circles connected by solid black lines). The remaining solutions are non-optimal (red crosses). The multiobjective optimization was performed for each of the ten different ASC configurations presented in Figure 2 by optimizing a bound set of parameters: Pt loading (intrinsic activity) of AMOX catalyst ( $\mathrm{Pt}=$ 0.01-6.11 wt.\% Pt on $\mathrm{TiO}_{2}$ and maximum of $61.1 \mathrm{mg} \mathrm{Pt} / \mathrm{L}_{\text {monolith), }}$ AMOX catalyst loading (AMOX = 1$60 \mathrm{~g} / \mathrm{L}_{\text {monolith }}$ ), SCR catalyst loading (SCR $=1-200 \mathrm{~g} / \mathrm{L}_{\text {monolith }}$ ), and average pore diameter (effective diffusivity) of catalyst layers $\left(d_{\text {pore }}=40-200 \mathrm{~nm}\right)$. These ranges and constraints were chosen to limit the system to reasonable design parameters.

The overall objective of the ASC optimization was the minimization of $\mathrm{NH}_{3}, \mathrm{NO}_{x}$, and $\mathrm{N}_{2} \mathrm{O}$ emissions. It should be noted that the optimization result is affected by the weighting, and as mentioned, an equal weighting based on the $\mathrm{N}$ atoms was applied to each emission. The resulting objective function for the multi-objective optimization problem was:

$$
\underset{w_{A M O X}, w_{S C R}, d_{\text {pore }, b l}, d_{\text {pore }, t l}, x_{\mathrm{Pt}}}{\operatorname{mat}} f=\left[\mathrm{NH}_{3}\right]_{\text {out }}+\left[\mathrm{NO}_{x}\right]_{\text {out }}+2 \times\left[\mathrm{N}_{2} \mathrm{O}\right]_{\text {out }}
$$

The optimization was completed using MATLAB's gamultiobj function, which employs the genetic algorithm for multi-objective optimization [37-39]. The genetic algorithm applies concepts of natural selection in biological evolution, to iteratively optimize a set of parameters for a given optimization problem [37]. In short, the optimization starts with a number of initial guesses, and for each guess, a score is determined according to the objective function (eq. 24). The next generation of guesses is generated, by changing and combining the initial guesses, where the score guides the probability that a given parameter set is included or not. By repeating this process, the parameter sets eventually evolve to the Pareto set. In this study, we have used a set of 50 initial guesses, multiplied by the number of parameters to vary, to account for the increase in possible solutions with the increase in parameters for the more complex configurations. The optimization was stopped after 10 iterations. The Pareto fronts resulting from the final set of optimal solutions were used to evaluate the sensitivity 
of the ASC performance to the possible ASC configurations. Further details can be found in supporting information.

\section{Results}

\subsection{Validation of the Kinetic Models}

Before we evaluate the performance of the different ASC configurations, we validate the kinetic models for ASC and SCR components separately. To validate the kinetic model for the ammonia oxidation catalyst, we have fitted the experimentally determined conversions of $\mathrm{NH}_{3}$ and the corresponding product distributions for the $1 \mathrm{wt} . \% \mathrm{Pt}_{\mathrm{TiO}} \mathrm{AMOX}$ catalyst in the temperature range $200-550^{\circ} \mathrm{C}$, as measured in a powder reactor, using the reaction scheme in Table 3 . The experimental and calculated data are compared in Figure 4; the corresponding kinetic parameters of the model fit are presented in Table 3. The good agreement between the measured and calculated values indicates that our model provides a satisfactory description of the behavior of the $1 \mathrm{wt} \% \mathrm{Pt} / \mathrm{TiO}{ }_{2} \mathrm{AMOX}$ catalyst.

The experimental data for $\mathrm{NH}_{3}$ oxidation show a steep decrease of the $\mathrm{NH}_{3}$ concentration as the temperature is increased from $200^{\circ} \mathrm{C}$ to $250^{\circ} \mathrm{C}$, reaching $50 \%$ conversion at $229^{\circ} \mathrm{C}$ and $100 \%$ at $250^{\circ} \mathrm{C}$. The $\mathrm{N}_{2}$ selectivity is high between $200-250^{\circ} \mathrm{C}$, with a maximum of $75 \% \mathrm{~N}_{2}$ selectivity at $230^{\circ} \mathrm{C}$. The $\mathrm{N}_{2} \mathrm{O}$ formation steeply increases at temperatures above $220^{\circ} \mathrm{C}$ as the $\mathrm{N}_{2}$ selectivity decreases, and a maximum of $49 \% \mathrm{~N}_{2} \mathrm{O}$ selectivity at $270^{\circ} \mathrm{C}$ is observed. Above $250^{\circ} \mathrm{C}$, the formation of $\mathrm{NO}$ becomes increasingly significant, while the product selectivity towards $\mathrm{N}_{2}$ and $\mathrm{N}_{2} \mathrm{O}$ decreases simultaneously. Furthermore, the formation of $\mathrm{NO}_{2}$ is seen to increase from $275^{\circ} \mathrm{C}$ to a maximum of $100 \mathrm{ppm} \mathrm{NO} \mathrm{N}_{2}$ at $450^{\circ} \mathrm{C}\left(20 \% \mathrm{NO}_{2}\right.$ selectivity). The maximum in $\mathrm{NO}_{2}$ is a result of the thermodynamic equilibrium for the $\mathrm{NO}+1 / 2 \mathrm{O}_{2} \leftrightarrow \mathrm{NO}_{2}$ reaction, which shifts towards $\mathrm{NO}$ above $450^{\circ} \mathrm{C}$ [40]. The model contains some rate coefficients with activation energies between $187-303 \mathrm{~kJ} / \mathrm{mol}$, which are necessary to describe the steep increase in $\mathrm{NH}_{3}$ conversion between 200 and $250^{\circ} \mathrm{C}$. We note that these are very high values for the activation energy. This indicates that the description of the $\mathrm{NH}_{3}$ ammonia oxidation reaction used here is probably too simple. Nevertheless, it describes the observed behavior of the Pt catalysts well, which is sufficient for modeling the catalytic performance.

Figure 5 shows a comparison of the measured and calculated conversions and product distributions for the performance of the $3.5 \mathrm{wt}$ \% Cu-Beta catalyst, the SCR component, using the reaction scheme in Table 4. For this SCR catalyst, we have considered (A) the oxidation of $\mathrm{NH}_{3}$, (B) NO oxidation, (C) $\mathrm{NO}_{2}$ decomposition, (D) standard SCR $\left(\mathrm{NO}_{2} / \mathrm{NO}_{x}=0\right)$, (E) slow SCR $\left(\mathrm{NO}_{2} / \mathrm{NO}_{x}=1\right)$, and $(\mathrm{F})$ fast $\mathrm{SCR}$ $\left(\mathrm{NO}_{2} / \mathrm{NO}_{\mathrm{x}}=0.5\right)$. The conditions for these reactions have been obtained by adjusting the concentrations of $\mathrm{NH}_{3}, \mathrm{NO}$, and $\mathrm{NO}_{2}$ in the reaction feed gas. For Figure $5 \mathrm{D}, \mathrm{E}$, and $\mathrm{F}$, the two points at $225^{\circ} \mathrm{C}$ are the result of overlap in measurements done with respectively 40 and $20 \mathrm{mg}$ catalyst. The kinetic parameters determined from parameter fitting, of the kinetic model for the SCR catalyst are presented in Table 4. For all reactions, the measured and calculated data show good agreement, indicating that the reaction scheme describes the behavior of the Cu-Beta SCR catalyst well.

From Figure $5 \mathrm{~A}$, the $3.5 \mathrm{wt}$.\% Cu-Beta catalyst becomes active for the oxidation of $\mathrm{NH}_{3}$ by $\mathrm{O}_{2}$ at about $300^{\circ} \mathrm{C}$, and reaches $80 \%$ conversion at $500^{\circ} \mathrm{C}$. This oxidation is very selective towards $\mathrm{N}_{2}$ with only 5 ppm $\mathrm{N}_{2} \mathrm{O}$ and 22 ppm $\mathrm{NO}_{x}$, which supports the decision not to include $\mathrm{NH}_{3}$ oxidation to $\mathrm{NO}_{x}$ or $\mathrm{N}_{2} \mathrm{O}$ in the SCR kinetic model. Furthermore, the oxidation of $\mathrm{NO}$ to $\mathrm{NO}_{2}$, and the $\mathrm{NO}_{2}$ decomposition (Figure $5 \mathrm{~B}$ and $\mathrm{C}$ ) are quite slow compared to the $\mathrm{Pt} / \mathrm{TiO}_{2}$ catalyst applied in this study.

The catalytic activity of the Cu-Beta catalyst for the standard SCR reaction is shown in Figure $5 \mathrm{D}$. Between 250 and $350^{\circ} \mathrm{C}$, the conversion of $\mathrm{NO}$ and $\mathrm{NH}_{3}$ changes less than one would expect from an 
Arrhenius-like behavior. Such behavior is known for $\mathrm{NH}_{3}$-SCR over Cu-zeolite based catalysts, in particular $\mathrm{Cu}-\mathrm{CHA}$, and is sometimes also observed as a decrease in $\mathrm{NO}_{x}$ conversion $[31,32,34,35]$. This behavior is an indication that the $\mathrm{NH}_{3}-\mathrm{SCR}$ reaction follows different mechanisms at low and high temperatures [34]. As discussed above, the kinetic model developed here for the Cu-Beta SCR catalyst includes a temperature dependent transition between two kinetic regimes of the standard SCR reactions (SCR.4 and SCR.5). The simulated $\mathrm{NO}_{x}$ conversion for the standard SCR operating conditions between $150-550^{\circ} \mathrm{C}$ is illustrated in Figure 6 . The contribution from each of the respective rate expressions is controlled by the fractions $x_{L T}$ and $x_{H T}$ as noted in Table 4. At temperatures below $220^{\circ} \mathrm{C}$, the standard SCR kinetics are $90 \%$ controlled by the low temperature kinetics. Above $220^{\circ} \mathrm{C}$, the contribution from the low temperature kinetics becomes smaller, reaching $50 \%$ at $260^{\circ} \mathrm{C}$ and $10 \%$ at $310^{\circ} \mathrm{C}$. By including this transition between the kinetic regimes of the standard SCR reactions (SCR.4 and SCR.5) in the kinetic model, it is able to accurately describe the non-Arrhenius behavior of the Cu-Beta catalyst for standard SCR.

\subsection{Validation of the Monolith Model}

In this section, the monolith ASC model is described and validated. To validate the ASC model, we compared measured outlet concentrations of $\mathrm{NH}_{3}, \mathrm{~N}_{2}, \mathrm{NO}_{x}$, and $\mathrm{N}_{2} \mathrm{O}$ for $\mathrm{NH}_{3}$ oxidation with calculated values according to the kinetics derived in Sections 3.2.1 and 3.2.2, as shown in Figure 7. The effective diffusivities of the gases in the catalyst layers are not known a priori, and therefore, the values for the diffusion coefficients are adjusted to fit the experimental data. To obtain a consistent set of diffusion coefficients for the different gases, the average pore diameter in each catalyst layer is varied manually to calculate the effective diffusion coefficients according to eqs. 10 and 11 . With a pore diameter 50 $\mathrm{nm}$, corresponding to $D_{\text {eff }}=1.38 \times 10^{-6} \mathrm{~m}^{2} / \mathrm{s}$ at $200^{\circ} \mathrm{C}$ for $\mathrm{NH}_{3}$, we find a good agreement between measured and calculated values for each catalyst layer in the single layer AMOX, single layer SCR, and dual layer configurations. For the single mixed layer catalyst, good agreement is obtained for a pore diameter of $15 \mathrm{~nm}$, corresponding to $D_{\text {eff }}=0.48 \times 10^{-6} \mathrm{~m} / \mathrm{s}^{2}$ at $200^{\circ} \mathrm{C}$ for $\mathrm{NH}_{3}$. This lower diffusion coefficient result from the intermixing and void filling of two powders with different particle sizes.

Figure 7 shows that the model describes the conversion of $\mathrm{NH}_{3}$ and the main trends in the product distributions well. The model follows the trend that a single layer AMOX catalyst has a high selectivity for $\mathrm{NO}_{x}$, which is significantly reduced by adding an SCR component. The formation of $\mathrm{N}_{2} \mathrm{O}$ over the AMOX catalyst is underestimated by the model in the temperature range $200-300^{\circ} \mathrm{C}$, due to a too high selectivity for $\mathrm{N}_{2}$, but the trend that the presence of an SCR component reduces the formation of $\mathrm{N}_{2} \mathrm{O}$ is reproduced. The differences between experimental and calculated data are similar to those observed in other studies [6,10-12]. Therefore, we conclude that the monolithic model, using the kinetic models based on fixed bed reactor data, reflects the behavior of the different catalyst systems quite well, which validates ASC model for our purpose.

\subsection{Optimization of ASC Configurations}

To further improve the understanding of the interplay between SCR and AMOX components in an ASC system, the expected performance of the ten possible ASC configurations shown in Figure 2 is calculated using the monolith model. In this study we focus on the effects of the loadings of SCR and AMOX catalyst, Pt loading (intrinsic activity) of the AMOX catalyst, and the average pore diameter (effective diffusivity) in the catalyst layers, for the ten configurations of the ASC monolith. By varying these parameters, we construct Pareto fronts for $\mathrm{NO}_{x}$ slip, $\mathrm{N}_{2} \mathrm{O}$ slip, combined $\mathrm{NO}_{x}$ and $\mathrm{N}_{2} \mathrm{O}$ slip, and $\mathrm{N}_{2}$ formed, all as a function of the $\mathrm{NH}_{3}$ slip, because the $\mathrm{NH}_{3}$ slip is the main performance parameter for an ASC. Table 5 summarizes the optimized data set, and the corresponding Pareto fronts are given 
in Figure 8. For the optimization, we have fixed the temperature to $300^{\circ} \mathrm{C}$, and otherwise used the same conditions as mentioned in the previous sections.

The Pareto fronts for the $\mathrm{NO}_{x}$ slip (Figure $8 \mathrm{~A}$ ) reflect the ability of the different ASC configurations to oxidize $\mathrm{NH}_{3}$ without forming $\mathrm{NO}_{x}$. For the majority of catalysts, the Pareto fronts overlap at a low $\mathrm{NO}_{x}$ slip; these catalysts all effectively have a mixed top layer. Two catalysts stand out in the graph, namely that for the single layer AMOX catalyst and the inverse dual layer configuration. In both configurations, the $\mathrm{Pt} / \mathrm{TiO}_{2}$ catalyst is exposed directly to the gas phase. The single layer AMOX catalyst produces the most $\mathrm{NO}_{x}$, and this is the known issue with this catalyst design $[3,5-13,15,17,19,20]$, and the reason why an SCR component is usually added to the ASC. The inverse dual layer consists of a top layer of AMOX catalyst, on a bottom layer of the SCR catalyst. Therefore, it also quite active in $\mathrm{NO}_{x}$ formation, although the presence of the SCR bottom layer greatly improves its $\mathrm{N}_{2}$ selectivity, compared to the single layer AMOX catalyst. The hybrid dual layer with an AMOX top layer, also leads to a significant $\mathrm{NO}_{x}$ slip. However, since this configuration has the option of mixing a significant part of the AMOX catalyst together with the SCR catalyst in the bottom layer, the selectivity for $\mathrm{NO}_{x}$ becomes lower than for the inverse dual layer configuration. Finally, the dual layer and the hybrid dual layer with an SCR top layer have a significant $\mathrm{NO}_{x}$ slip at high $\mathrm{NH}_{3}$ conversion, because high ammonia conversion comes with an increased accessibility to the AMOX catalyst, leading to an increase in $\mathrm{NO}_{x}$ formation. This means that in these configurations, the $\mathrm{NO}_{x}$ slip is always lowered at the cost of $\mathrm{NH}_{3}$ conversion.

In the trade-off for $\mathrm{NH}_{3}$ conversion and $\mathrm{N}_{2} \mathrm{O}$ formation (Figure $8 \mathrm{~B}$ ), the optimized single layer AMOX, dual layer, and inverse dual layer catalysts show the highest $\mathrm{N}_{2} \mathrm{O}$ selectivity. The largest contribution for $\mathrm{N}_{2} \mathrm{O}$ formation comes from the reaction of $\mathrm{NO}$ and $\mathrm{NH}_{3}$ over Pt (Table 3, AMOX.4). These catalyst configurations contain a single pure layer of $\mathrm{AMOX}$ catalyst, which thus leads to a high $\mathrm{N}_{2} \mathrm{O}$ formation. Unexpectedly, the $\mathrm{N}_{2} \mathrm{O}$ slip from the hybrid dual layer with an AMOX top layer configuration is one of the lowest even though the catalyst includes a pure top layer of AMOX catalyst. This is due to a combination of a moderate intrinsic activity of the AMOX catalyst and a high effective diffusivity, which limits the reaction between $\mathrm{NH}_{3}$ and $\mathrm{NO}$ to $\mathrm{N}_{2} \mathrm{O}$ over the AMOX catalyst. All catalysts with mixed layers of AMOX and SCR catalyst show a low $\mathrm{N}_{2} \mathrm{O}$ slip, since the SCR catalyst ensures a fast reaction between $\mathrm{NO}_{x}$ and $\mathrm{NH}_{3}$ leaving little chance for these species to react to $\mathrm{N}_{2} \mathrm{O}$ over the AMOX catalyst.

Figure $8 \mathrm{C}$ shows the Pareto fronts for the combination of the $\mathrm{NO}_{x}$ slip and $\mathrm{N}_{2} \mathrm{O}$ slip, which is the objective function that has been used in the optimization (eq. 12). In general, the observations are similar to those from Figure $8 \mathrm{~A}$ and $\mathrm{B}$ : The catalysts that are most selective in oxidizing $\mathrm{NH}_{3}$ to $\mathrm{NO}_{x}$ and $\mathrm{N}_{2} \mathrm{O}$ are the single layer AMOX, inverse dual layer, and dual layer, while the mixed layer catalysts are overlaying, and the least selective towards $\mathrm{NO}_{x}$ and $\mathrm{N}_{2} \mathrm{O}$ (most selective to $\mathrm{N}_{2}$ ).

The Pareto fronts for the $\mathrm{N}_{2}$ formation (Figure $8 \mathrm{D}$ ) represent the optimized yields of $\mathrm{N}_{2}$ that can be obtained for the different ASC configurations. The dashed gray line represents the $\mathrm{N}_{2}$ selectivity of an ideal ASC, for which $\mathrm{NH}_{3}$ is only oxidized to $\mathrm{N}_{2}$. For most curves, a maximum in these curves indicates an optimal solution for the given configuration. From Figure $8 \mathrm{D}$, we see that the most effective catalysts for oxidizing $\mathrm{NH}_{3}$ to $\mathrm{N}_{2}$ are those that contain mixed layers in the top. By combining the AMOX and SCR components, the $\mathrm{NH}_{3}$ oxidation activity is balanced with the $\mathrm{NO}_{x}$ reduction leading to a significant improvement in the selective oxidation of $\mathrm{NH}_{3}$ to $\mathrm{N}_{2}$.

A comparison of the composition of the ten ASC configurations at their peak performance (minimum in the objective function, Table 5), shows that the configurations generally favor a high effective diffusivity (max $d_{\text {pore }}$ of $200 \mathrm{~nm}$ ) and use almost all the available SCR and Pt (maximum allowable 
levels of $200 \mathrm{~g} / \mathrm{L}_{\text {mobolith }}$ and $\left.61.1 \mathrm{mg} \mathrm{P}_{\mathrm{P}} / \mathrm{L}_{\text {monolith }}\right)$. The most efficient utilization of the raw materials is obtained for configurations with mixed layers, in particular the dual mixed layer, hybrid dual layer with an AMOX top layer, and inverse hybrid dual layer with SCR bottom layer configurations.

\section{Discussion}

The results from multi-objective optimization of the ten different ASC configurations presented contribute to the understanding of the ASC. In general, the performance of the ASC is highly dependent on the $\mathrm{Pt}$ loading ( $\mathrm{mg}_{\mathrm{Pt}} / \mathrm{L}_{\text {monolith }}$ ), since an absence of $\mathrm{Pt}$ results in a lack of $\mathrm{NH}_{3}$ oxidation activity. This is most clearly observed at temperatures below $300^{\circ} \mathrm{C}$ where the rate of $\mathrm{NH}_{3}$ oxidation is limited by the reaction kinetics. However, if the oxidation activity is sufficiently high, the rate of $\mathrm{NH}_{3}$ oxidation becomes controlled by internal or external mass transfer limitations. At this point, the catalyst loading (layer thickness) and effective diffusivity of the catalyst layers become increasingly significant.

The thickness of the catalyst layer is affected by variations in catalyst loading, and this also affects the rate of the diffusion through catalyst layers. As a consequence, it is more beneficial to apply a low loading of an AMOX catalyst with a higher Pt loading (catalyst with high intrinsic activity), thereby keeping diffusion limitations to a minimum. Especially for the dual layer catalyst, diffusion properties are an important design parameter, since the SCR top layer is acting as a diffusion barrier for $\mathrm{NH}_{3}$ to the AMOX catalyst, while also providing the necessary SCR activity. This has also been shown by recent investigations where macro-porosity was introduced into the SCR layer of a dual layer ASC using yeast or polymers, to enhance mass transport to the AMOX layer [16]. For the single mixed layer catalyst, the key design parameter is the SCR catalyst loading since it is used to balance the $\mathrm{NH}_{3}$ oxidation activity with the SCR activity, in effect determining product selectivity of the ASC. The effective diffusivity is still significant in ensuring a high effectiveness factor, but is less critical than the SCR loading for the dual layer catalysts.

In our simulations, the mass transfer resistance in the catalyst layers is described by the diffusion coefficients in these layers. We have estimated the diffusion coefficients by including the contribution of Knudsen diffusion (eqs. 10 and 11) and have adjusted the pore diameters in the catalyst layers, using constant values of the porosity $(\epsilon=0.4)$ and tortuosity $(\tau=3)$; these are typical values for randomly packed beds. Using pore diameters of 15 and $50 \mathrm{~nm}$, which is in the correct order of magnitude for a washcoat layer [24], we obtain values of the diffusion coefficients that result in the experimentally observed conversion levels. Neglecting Knudsen diffusion for pore sizes in this range may lead to using unrealistic values of the tortuosity to fit the data from washcoated monoliths [12].

The multi-objective optimization of the ten ASC configurations points to the combinations of intrinsic activity, catalyst loading, and effective diffusivity, that lead to minimal emissions for a given catalyst configuration. Based on the solutions we have found, it becomes clear that ASC configurations with mixed layers perform best and utilize the catalyst material most efficiently, as seen in the following ranking:

$$
\left(\frac{\text { AMOX }+ \text { SCR }}{\text { AMOX }+ \text { SCR }}\right) \approx\left(\frac{\text { AMOX }}{\text { AMOX }+ \text { SCR }}\right) \approx\left(\frac{\text { AMOX+ SCR }}{\text { SCR }}\right)>\left(\frac{\text { SCR }}{\text { AMOX }+ \text { SCR }}\right) \approx\left(\frac{}{\text { AMOX }+ \text { SCR }}\right)>\left(\frac{\text { AMOX }+ \text { SCR }}{\text { AMOX }}\right)>\left(\frac{\text { AMOX }}{\text { SCR }}\right)>\left(\frac{\text { SCR }}{\text { AMOX }}\right)>>\left(\frac{}{\text { AMOX }}\right)>\left(\frac{}{\text { SCR }}\right)
$$

According to our current understanding, there are two factors that determine this behavior. First, the good accessibility of the AMOX component ensures a high conversion of $\mathrm{NH}_{3}$. Second, the immediate vicinity of the SCR catalyst reduces the concentrations of $\mathrm{NO}$ and $\mathrm{NH}_{3}$ at the Pt-based AMOX catalyst, thus avoiding formation of unwanted $\mathrm{N}_{2} \mathrm{O}$ and improving the selectivity to $\mathrm{N}_{2}$. 
It should be emphasized that the validity of the optimization presented can be further expanded. First, we have used a single temperature of $300^{\circ} \mathrm{C}$ and fixed other conditions, such as flow and feed gas composition (i.e. no $\mathrm{NO}_{x}$ in the feed). Furthermore, a transient model allowing for variable inlet gas composition, flow rate and temperature would enable a more direct comparison with real world applications. The second limitation is that the result depends on the relative weighting of the emissions in the objective functions. These limitations will influence the outcome of the optimization. For example, an SCR top layer could be more advantageous if $\mathrm{NO}_{x}$ is present in the feed along with $\mathrm{NH}_{3}$ or at higher temperatures where the SCR catalyst is active for selective oxidation of $\mathrm{NH}_{3}$. Furthermore, in our optimization, the $\mathrm{NH}_{3}$ conversion was weighted equally with $\mathrm{NO}_{x}$ and $\mathrm{N}_{2} \mathrm{O}$ selectivity, but this is an arbitrary choice, and a different weighting of these factors will result in different optimized formulations. Our approach of combining reactor models and relevant design parameters to determine Pareto fronts, offers a useful tool to evaluate the effect of the design parameters simultaneously, and decide how to balance the different properties, such as activity, diffusivity, and amounts of catalyst, in order to reach the optimal performance.

\section{Conclusion}

An ammonia slip catalyst (ASC) combines the high activity of the ammonia oxidation (AMOX) catalyst with the efficiency of selective catalytic reduction of $\mathrm{NO}_{x}$ with $\mathrm{NH}_{3}$ over an SCR catalyst $\left(\mathrm{NH}_{3}-\mathrm{SCR}\right)$, to ensure minimal $\mathrm{NH}_{3}$ slip and limited formation of $\mathrm{NO}_{x}$ and $\mathrm{N}_{2} \mathrm{O}$.

In order to investigate and compare optimal solutions of different ASC configurations, an extensive flow reactor study using powder catalysts was carried out to determine the intrinsic kinetics of the relevant reactions over $1 \mathrm{wt} . \% \mathrm{Pt} / \mathrm{TiO}_{2}$ (AMOX) and $3.5 \mathrm{wt}$ \% $\mathrm{Cu}$-Beta (SCR). The Cu-Beta SCR kinetic model accounts for the non-Arrhenius behavior, by a transition between low temperature and high temperature kinetics. A 1D-1D (pseudo 2D) mathematical model of a monolithic ASC, implementing the derived intrinsic kinetics of the catalysts, was developed and fitted to experimental data using four different small scale monoliths, using the pore size of the ASC layers as fitting parameter. The model describes well the $\mathrm{NH}_{3}$ conversion and $\mathrm{NO}_{x}$ yields, and to a reasonable extent the yields of $\mathrm{N}_{2} \mathrm{O}$ and $\mathrm{N}_{2}$ over the four small scale monoliths.

The performance of ten different ASC configurations was investigated by using the model to perform a multi-objective optimization of $\mathrm{NH}_{3}$ oxidation at $300^{\circ} \mathrm{C}$, by varying the intrinsic activity of the AMOX catalyst (Pt content), the loadings of the AMOX and SCR catalysts, and the effective diffusivity of the catalyst layers. The resulting Pareto fronts indicate that the most effective catalyst designs are those that contain a thin top layer, has high effective diffusivity in the layers, and use a high mixed layer load.

Catalyst configurations with pure layers of AMOX catalyst generally produce the most $\mathrm{N}_{2} \mathrm{O}$, identifying the Pt-based AMOX catalyst as the main source of $\mathrm{N}_{2} \mathrm{O}$. In configurations with only an SCR catalyst in the top layer, the $\mathrm{NH}_{3}$ conversion can be increased using either a thinner or a more open layer of the SCR catalyst, since the top layer acts as a diffusion barrier for $\mathrm{NH}_{3}$ to reach the AMOX catalyst. This, however, leads to a high $\mathrm{NO}_{x}$ selectivity at high $\mathrm{NH}_{3}$ conversion. Overall, ASC's with mixed layers provide the highest $\mathrm{NH}_{3}$ conversion, due to the accessibility to the AMOX catalyst for $\mathrm{NH}_{3}$, while $\mathrm{SCR}$ catalyst in the immediate vicinity keeps the concentrations of $\mathrm{NO}_{x}$ and $\mathrm{NH}_{3}$ at a low level, which suppresses the formation of $\mathrm{N}_{2} \mathrm{O}$ over the AMOX catalyst. 


\section{Declarations}

\section{Conflict of Interest}

On behalf of all authors, the corresponding author states that there is no conflict of interest.

\section{Funding}

The financial support from Innovation Fund Denmark under Grant Number 103-2012-3 is gratefully acknowledged. 


\section{Nomenclature}

Abbreviations:
AMOX Ammonia oxidation
ASC Ammonia slip catalyst
cpsi Cells per square inch
FTIR Fourier-transform infrared spectroscopy
GHSV Gas hourly space velocity $\left(\mathrm{hr}^{-1}\right)$
$\mathrm{NO}_{x} \quad$ Nitrogen oxides $\left(\mathrm{NO}\right.$ and $\left.\mathrm{NO}_{2}\right)$
SCR Selective catalytic reduction

\section{Arabic Letters:}$$
\text { A }
$$

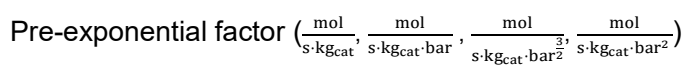

$A_{S}$

External surface area of catalyst washcoat per tank $\left(\mathrm{m}^{2}\right)$

$C_{g}$

Gas phase concentration $\left(\mathrm{mol} / \mathrm{m}^{3}\right)$

$C_{s} \quad$ Concentration at the surface of the catalyst washcoat $\left(\mathrm{mol} / \mathrm{m}^{3}\right)$

$C_{w c} \quad$ Concentration in the washcoat phase $\left(\mathrm{mol} / \mathrm{m}^{3}\right)$

$D_{\text {bulk }} \quad$ Bulk diffusion coefficient $\left(\mathrm{m}^{2} / \mathrm{s}\right)$

$D_{\text {eff }} \quad$ Effective diffusion coefficient $\left(\mathrm{m}^{2} / \mathrm{s}\right)$

$D_{K} \quad$ Knudsen diffusion coefficient $\left(\mathrm{m}^{2} / \mathrm{s}\right)$

$d \quad$ Diameter of monolith sample $(\mathrm{m})$

$d_{H} \quad$ Hydraulic diameter of the coated channel $(\mathrm{m})$

$d_{\text {pore }} \quad$ Average pore diameter $(\mathrm{m})$

$E_{A} \quad$ Activation energy $(\mathrm{J} / \mathrm{mol})$

$f \quad$ Fitness function (ppm)

$K_{e q} \quad$ Equilibrium constant for thermodynamic equilibrium of $\mathrm{NO}$ and $\mathrm{NO}_{2}()$

$K_{e q, x} \quad$ Equilibrium constant for describing transfer between kinetic regimes of SCR catalyst ()

$k \quad$ Reaction rate coefficient $\left(\frac{\mathrm{mol}}{\mathrm{s} \cdot \mathrm{kgcat}}, \frac{\mathrm{mol}}{\mathrm{s} \cdot \mathrm{kg} \mathrm{cat} \cdot \mathrm{bar}}, \frac{\mathrm{mol}}{\left.\mathrm{s} \cdot \mathrm{kg} \mathrm{cat} \cdot \mathrm{bara}^{\frac{3}{2}}, \frac{\mathrm{mol}}{\mathrm{s} \cdot \mathrm{kg} \text { cat } \cdot \mathrm{bar}^{2}}\right)}\right)$

$k_{m t} \quad$ Mass transfer coefficient $(\mathrm{m} / \mathrm{s})$

$L \quad$ Length of monolith sample $(\mathrm{m})$ 


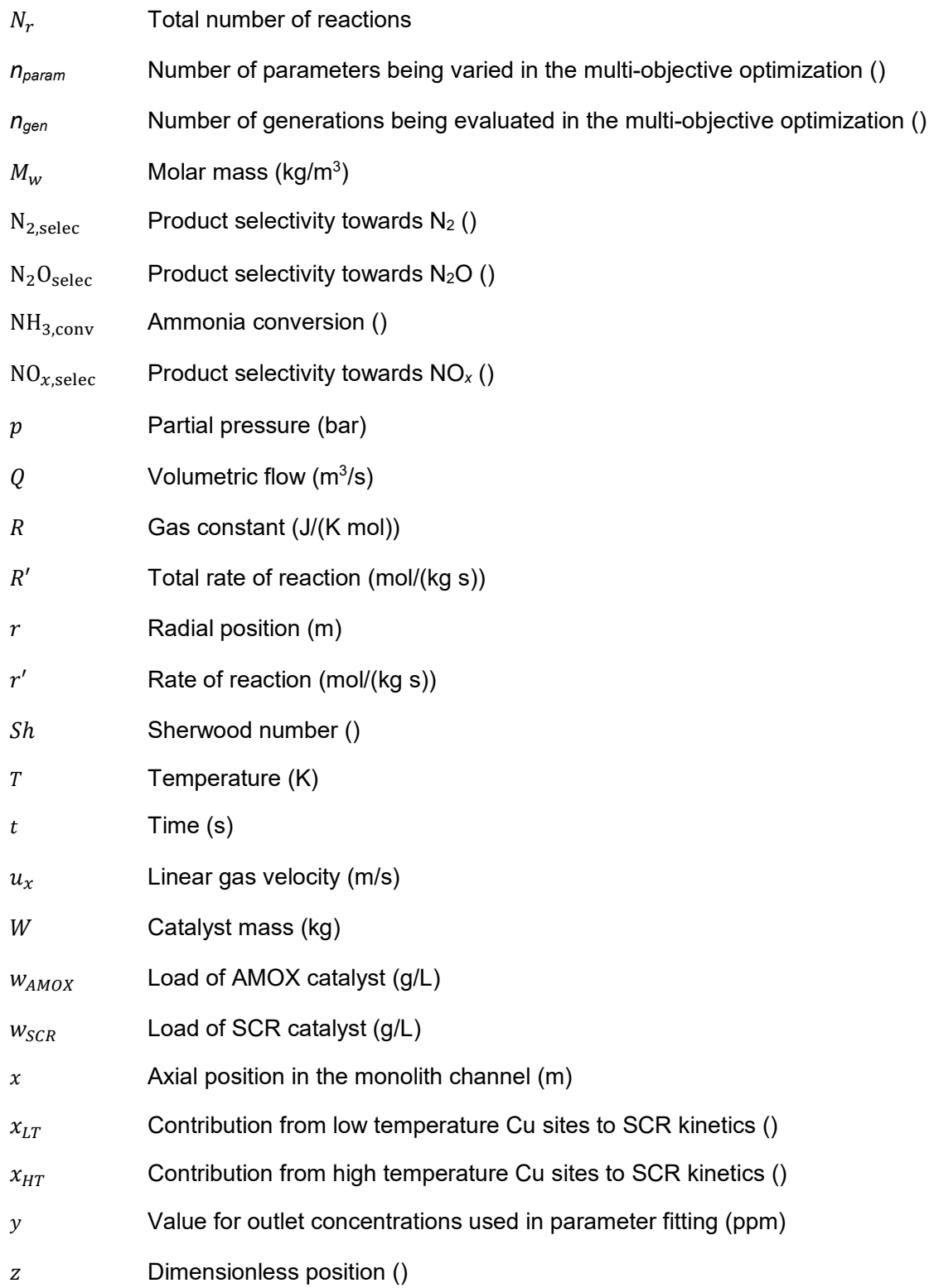




\section{Greek symbols:}

$\Omega \quad$ Adsorption capacity of the catalyst ( $\left.\mathrm{mol} / \mathrm{kg}_{\mathrm{cat}}\right)$

$\theta \quad$ Surface coverage of the catalyst with adsorbed reactant ()

$\Delta H \quad$ Reaction enthalpy $(\mathrm{J} / \mathrm{mol})$

$\Delta S \quad$ Entropy $(\mathrm{J} /(\mathrm{mol} \mathrm{K}))$

$\rho \quad$ Catalyst density $\left(\mathrm{kg}_{\text {cat }} / \mathrm{m}^{3}\right)$

$\phi \quad$ Volume fraction of catalyst in layer ()

$v \quad$ Stoichiometric reaction coefficient ()

$\epsilon \quad$ Porosity ()

$\tau \quad$ Tortuosity ()

$\chi_{\mathrm{Pt}} \quad$ Pt content of AMOX catalyst (wt.\%)

\section{Subscript and superscript}

bl Bottom layer of ammonia slip catalyst

cat $\quad$ Catalyst (AMOX or SCR)

exp Experimental value

$g \quad$ Gas phase

$g / t l \quad$ Interface of between gas phase and top layer

$i \quad$ Species $i$

in Inlet

interface Interface between bottom layer and top layer

j Reaction $j$

out Outlet

sim Simulated

tl Top layer of ammonia slip catalyst

wall Monolith wall

$w c \quad$ Catalyst washcoat phase

wc/wall Interface between washcoat and monolith wall 


\section{References}

[1] European Union: Commision Regulation (EU) No 582/2011. OJ. 25.6, 1-168 (2011).

[2] Environmental Protection Agency: Control of Air Pollution From New Motor Vehicles: HeavyDuty Engine and Vehicle Standards and Highway Diesel Fuel. Fed. Regist. 66, 5001-5193 (2001).

[3] Walker, A.: Future Challenges and Incoming Solutions in Emission Control for Heavy Duty Diesel Vehicles. Top. Catal. 59, 695-707 (2016).

[4] Janssens, T., Falsig, H., Lundegaard, L., Vennestrøm, P., Rasmussen, S., Moses, P., Giordanino, F., Borfecchia, E., Lomachenko, K., Lamberti, C., Bordiga, S., Godiksen, A., Mossin, S., Beato, P.: A Consistent Reaction Scheme for the Selective Catalytic Reduction of Nitrogen Oxides with Ammonia. ACS Catal. 5, 2832-2845 (2015).

[5] Scheuer, A., Hauptmann, W., Drochner, A., Gieshoff, J., Vogel, H., Votsmeier, M.: Dual Layer Automotive Ammonia Oxidation Catalysts: Experiments and Computer Simulation. Appl. Catal. B. 111-112, 445-455 (2012).

[6] Shrestha, S., Harold, M., Kamasamudram, K., Yezerets, A.: Ammonia Oxidation on Structured Composite Catalysts. Top. Catal. 56, 182-186 (2013).

[7] Colombo, M., Nova, I., Tronconi., E.: A Simplified Approach to Modeling of Dual-layer Ammonia Slip Catalysts. Chem. Eng. Sci. 75, 75-83 (2012).

[8] Colombo, M., Nova, I., Tronconi, E., Schmeißer, V., Bandl-Konrad, B., Zimmermann, L.R.: Experimental and Modeling Study of a Dual-Layer (SCR + PGM) $\mathrm{NH}_{3}$ Slip Monolith Catalyst (ASC) for Automotive SCR Aftertreatment Systems. Part 1. Kinetics for the PGM Component and Analysis of SCR/PGM Interactions. Appl. Catal. B. 142-143, 861-876 (2013).

[9] Scheuer, A., Drochner, A., Gieshoff, J., Vogel, H., Votsmeier, M.: Runtime Efficient Simulation of Monolith Catalysts with a Dual-Layer Washcoat. Catal. Today. 188, 70-79 (2012).

[10] Shrestha, S., Harold, M., Kamasamudram, K., Kumar, A., Olsson, L., Leistner, K.: Selective Oxidation of Ammonia to Nitrogen on Bi-functional Cu-SSZ-13 and Pt/Al $\mathrm{O}_{3}$ Monolith Catalyst. Catal. Today. 267, 130-144 (2016).

[11] Shrestha, S., Harold, M., Kamasamudram, K., Yezerets, A.: Selective Oxidation of Ammonia on Mixed and Dual-layer Fe-ZSM-5 + $\mathrm{Pt}^{\mathrm{A}} / \mathrm{Al}_{2} \mathrm{O}_{3}$ Monolithic Catalysts. Catal. Today. 231, 105-115 (2014).

[12] Shrestha, S., Harold, M., Kamasamudram K.: Experimental and Modeling Study of Selective Ammonia Oxidation on Multi-functional Washcoated Monolith Catalysts. Chem. Eng. J. 278, 24-35 (2015).

[13] Scheuer, A., Votsmeier, M., Schuler, A., Gieshoff, J., Drochner, A., Vogel, $\mathrm{H}_{\text {.: }} \mathrm{NH}_{3}-\mathrm{Slip}$ Catalysts: Experiments Versus Mechanistic Modelling. Top. Catal. 52, 1847-1851 (2009). 
[14] Dhillon, P., Harold, M., Wang, D., Kumar, A., Joshi, S.Y.: Optimizing the Dual-layer $\mathrm{Pt} / \mathrm{Al}_{2} \mathrm{O}_{3}+$ $\mathrm{Cu} / \mathrm{SSZ}-13$ Washcoated Monolith: Selective Oxidation of $\mathrm{NH}_{3}$ to $\mathrm{N}_{2}$. Catal. Today. (2020).

[15] Colombo, M., Nova, I., Tronconi, E., Koltsakis, G.: A Modeling Study of $\mathrm{NH}_{3}$ Slip Catalysts: Analysis of the SCR/PGM Interactions. Top. Catal. 56, 177-181 (2013).

[16] Dhillon, P., Harold, M., Wang, D., Kumar, A., Joshi, S.: Enhanced Transport in Washcoated Monoliths: Application to Selective Lean NOx Reduction and Ammonia Oxidation. Chem. Eng. J. 377 (2019).

[17] Colombo, M., Nova, I., Tronconi, E., Schmeißer, V., Bandl-Konrad, B., Zimmermann, L.R.: Experimental and Modeling Study of a Dual-Layer (SCR + PGM) $\mathrm{NH}_{3}$ Slip Monolith Catalyst (ASC) for Automotive SCR Aftertreatment Systems. Part 2. Validation of PGM Kinetics and Modeling of the Dual-layer ASC Monolith. Appl. Catal. B. 142-143, 337-343 (2013).

[18] Nova, I., Ciardelli, C., Tronconi, E., Chatterjee, D., Weibel, M.: $\mathrm{NH}_{3}-\mathrm{NO} / \mathrm{NO}_{2}$ SCR for Diesel Exhausts After Treatment: Mechanism and Modelling of a Catalytic Converter. Top. Catal. 4243, 43-46 (2007).

[19] Nova, I., Colombo, M., Tronconi, E., Schmeißer, V., Bandl-Konrad, B., Zimmermann, L. L.R.: Experimental and Modelling Study of a Dual-Layer $\mathrm{NH}_{3}$ Slip Monolith Catalyst for Automotive SCR Aftertreatment Systems. Top. Catal. 56, 227-231 (2013).

[20] Votsmeier, M., Scheuer, A., Drochner, A., Vogel, H., Gieshoff, J.: Simulation of Automotive $\mathrm{NH}_{3}$ Oxidation Catalysts Based on Pre-computed Rate Data from Mechanistic Surface Kinetics. Catal. Today. 151, 271-277 (2010).

[21] Metkar, P., Harold, M., Balakotaiah, V.: Experimental and Kinetic Modeling Study of $\mathrm{NH}_{3}-\mathrm{SCR}$ of $\mathrm{NO}_{\times}$on Fe-ZSM-5, Cu-chabazite and Combined Fe-and Cu-zeolite Monolithic Catalysts. Chem. Eng. Sci. 87, 51-66 (2013).

[22] Tronconi, E., Forzatti, P.: Adequacy of Lumped Parameter Models for SCR Reactors with Monolith Structure. AICHE J. 38, 201-210 (1992).

[23] Karamitros, D., Koltsakis, G.: Chapter 13 SCR Reactor Models for Flow-Through and WallFlow Converters. In: Nova, I., Tronconi, E. (eds.) Urea-SCR Technology for deNOx After Treatment of Diesel Exhausts, pp. 385-424. Springer, New York (2014).

[24] Dudák, M., Novák, V., Kočí, P., Marek, M., Blanco-García, P., Jones, G.: Prediction of Diffusivity and Conversion of n-Decane and $\mathrm{CO}$ in Coated $\mathrm{Pt} / \mathrm{Al}_{2} \mathrm{O}_{3}$ Catalyst Depending on Porous Layer Morphology. Appl. Catal. B. 150-151, 446-458 (2014).

[25] Dhillon, P., Harold, M., Wang, D., Kumar, A., Joshi, S.: Hydrothermal Aging of $\mathrm{Pt} / \mathrm{Al}_{2} \mathrm{O}_{3}$ Monolith: Washcoat Morphology Degradation Effects Studied using Ammonia and Propylene Oxidation. Catal. Today. 320, 20-29 (2019). 
[26] Fogler, H.: Chapter 12 Diffusion and Reaction. In: Fogler, H. Elements of Chemical Reaction Engineering, pp. 813-866. Pearson Education (2006).

[27] Rawlings, J.B., Ekerdt, J.G.: Chemical Reactor Analysis and Design Fundamentals. Nob Hill Publishing (2002).

[28] Kraehnert, R., Baerns, M.: Kinetics of Ammonia Oxidation over Pt Foil Studied in a Microstructured Quartz-reactor. Chem. Eng. J. 137, 361-375 (2008).

[29] National Institute of Standards and Technology (NIST): NIST Chemistry Webbook. http://webbook.nist.gov/chemistry/. Accessed: January $5^{\text {th }}, 2015$.

[30] Mihai, O., Widyastuti, C., Andonova, S., Kamasamudram, K., Li, J., Joshi, S., Currier, N., Yezerets, A., Olsson, L.: The Effect of Cu-loading on Different Reactions Involved in $\mathrm{NH}_{3}$-SCR over Cu-BEA Catalysts. J. Catal. 311, 170-181 (2014).

[31] Kamasamudram, K., Currier, N., Szailer, T., Yezerets, A.: Why Cu- and Fe-Zeolite SCR Catalysts Behave Differently At Low Temperatures. SAE Int. J. Fuels Lubr. 3, 664-672 (2010).

[32] Gao, F., Walter, E., Kollar, M., Wang, Y., Szanyi, J., Peden, C.: Understanding Ammonia Selective Catalytic Reduction Kinetics over Cu/SSZ-13 from Motion of the Cu lons. J. Catal. 319, 1-14 (2014).

[33] Paolucci, C., lorio, J.D., Ribeiro, F., Gounder, R., Schneider, W.: Catalysis Science of NOx Selective Catalytic Reduction With Ammonia Over Cu-SSZ-13 and Cu-SAPO-34. Adv. Catal. 59, 1-107 (2016).

[34] Gao, F., Mei, D., Wang, Y., Szanyi, J., Peden, C.: Selective Catalytic Reduction over Cu/SSZ13: Linking Homo- and Heterogeneous Catalysis. J. Am. Chem. Soc. 139, 4935-4942 (2017).

[35] Paolucci, C., Khurana, I., Parekh, A.A., Li, S., Shih, A.J., Li, H., Di lorio, J.R., AlbarracinCaballero, J.D., Yezerets, A., Miller, J.T., Delgass, W.N., Ribeiro, F.H., Schneider, W.F., Gounder, R.: Dynamic Multinuclear Sites Formed. Science 357 (2017).

[36] Chen, L., Janssens, T., Skoglundh, M., Grönbeck, $\mathrm{H} .:$ Interpretation of $\mathrm{NH}_{3}$-TPD Profiles from Cu-CHA Using First-Principles Calculations. Top. Catal. 62, 93-99 (2019).

[37] MathWorks: What Is the Genetic Algorithm? se.mathworks.com/help/gads/what-is-the-geneticalgorithm.html. Accessed: April 26th, 2017.

[38] MathWorks: Genetic Algorithm Terminology. se.mathworks.com/help/gads/some-geneticalgorithm-terminology.htmls. Accessed: April 26th, 2017.

[39] MathWorks: How the Genetic Algorithm Works. se.mathworks.com/help/gads/how-the-geneticalgorithm-works.html. Accessed: April 26th, 2017. 
[40] Hansen, T.K., Høj, M., Hansen, B.B., Janssens, T.V.W., Jensen, A.D.: The Effect of Pt Particle Size on the Oxidation of $\mathrm{CO}, \mathrm{C}_{3} \mathrm{H}_{6}$, and $\mathrm{NO}$ over $\mathrm{Pt} / \mathrm{Al}_{2} \mathrm{O}_{3}$ for Diesel Exhaust Aftertreatment. Top. Catal. 60, 1333-1344 (2017). 
Tables and Figures:

Table 1: Overview of the monolithic ammonia slip catalysts prepared by dip coating with slurries of $1 \mathrm{wt. \%}$ $\mathrm{Pt} / \mathrm{TiO}_{2}$ (AMOX) and/or 3.5 wt.\% Cu-Beta zeolite (SCR).

\begin{tabular}{lccc}
\hline Sample & $\begin{array}{c}\text { AMOX Loading } \\
\text { (g }\end{array}$ & $\begin{array}{c}\text { Pt Loading } \\
\left.\text { (mg } / \mathbf{L}_{\text {monolith }} / \mathbf{L}_{\text {monolith }}\right)\end{array}$ & $\begin{array}{c}\text { SCR Loading } \\
\text { (g) }\end{array}$ \\
\hline Single layer AMOX & 26 & 61.1 & 0 \\
Single layer SCR & 0 & 0 & 61 \\
Single mixed layer & 12 & 120 & 110 \\
Dual layer & 26 & 61.1 & 54 \\
\hline
\end{tabular}

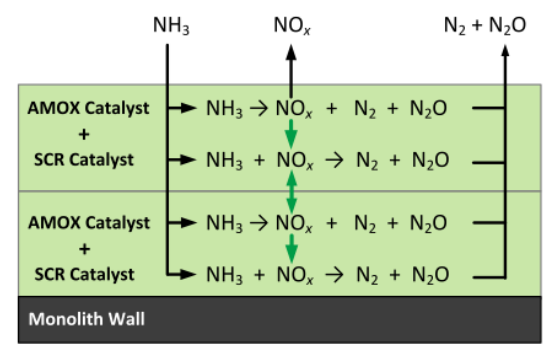

Figure 1: Illustration of the dual mixed layer (DML) ammonia slip catalyst configuration, which the ASC monolith model was based on. 


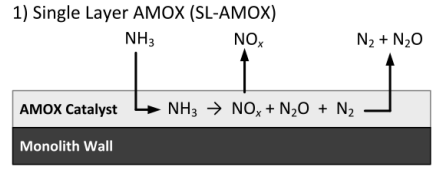

3) Dual Layer (DL)

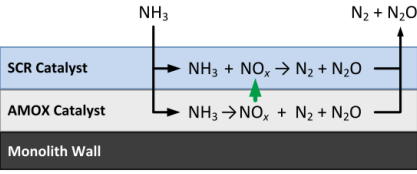

5) Hybrid Dual Layer - SCR Split (HDL-S)

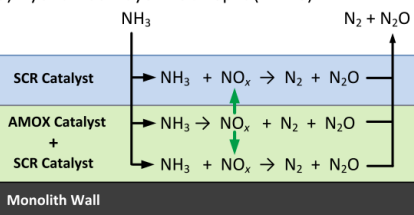

7) Hybrid Dual Layer - AMOX Split (HDL-A)

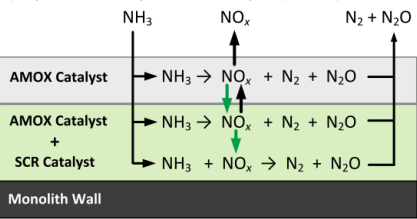

9) Single Mixed Layer (SML)

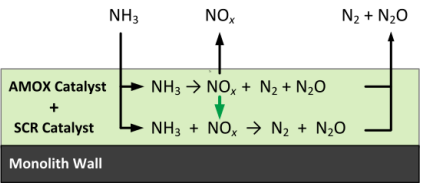

2) Single Layer SCR (SL-SCR)

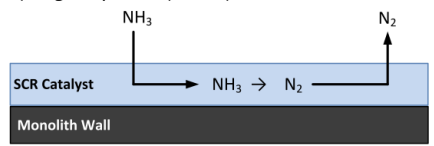

4) Inverse Dual Layer (IDL)

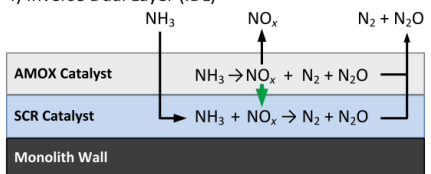

6) Inverse Hybrid Dual Layer - SCR Split (IHDL-S)

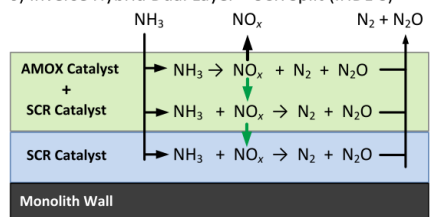

8) Inverse Hybrid Dual Layer - AMOX Split (IHDL-A)

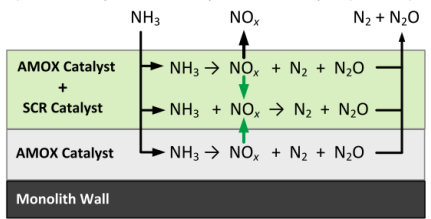

10) Dual Mixed Layers (DML)

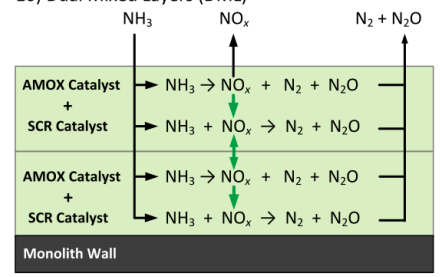

Figure 2: The ten possible ammonia slip catalyst configurations that can be simulated using the dual mixed layer model. 1) single layer AMOX (SL-AMOX), 2) single layer SCR (SL-SCR), 3) dual layer (DL), 4) inverse dual layer $(I D L), 5)$ hybrid dual layer with top layer of SCR (HDL-S), 6) inverse hybrid dual layer with bottom layer of SCR (IHDL-S), 7) hybrid dual layer with top layer of AMOX (HDL-A), 8) inverse hybrid dual layer with bottom layer of AMOX (IHDL-A), 9) single mixed layer (SML), and 10) dual mixed layer (DML). 
Table 2: Expressions for the bulk diffusion coefficients as a function of temperature at atmospheric conditions [21].

\begin{tabular}{lc}
\hline Species & Diffusion Coefficient $\left(\mathbf{m}^{2} / \mathbf{s}\right)$ \\
\hline $\mathrm{NH}_{3}$ & $1.215 \times 10^{-9} \cdot T^{1.7389}$ \\
$\mathrm{NO}$ & $1.2365 \times 10^{-9} \cdot T^{1.7006}$ \\
$\mathrm{NO}_{2}$ & $7.9236 \times 10^{-10} \cdot T^{1.7297}$ \\
$\mathrm{~N}_{2} \mathrm{O}$ & $8.1452 \times 10^{-10} \cdot T^{1.7314}$ \\
\hline
\end{tabular}

Table 3: Kinetic model for the $1 \mathrm{wt.} \% \mathrm{Pt} / \mathrm{TiO}_{2}$ AMOX catalyst at $5 \mathrm{vol} . \% \mathrm{H}_{2} \mathrm{O}$ and $10 \mathrm{vol} . \% \mathrm{O}_{2}$.

\begin{tabular}{lllll}
\hline Reaction \# & Reaction & Rate Expression $\left(\frac{\text { mol }}{\mathbf{s} \text { kg cat }}\right)$ & $\boldsymbol{A}_{\boldsymbol{j}}$ & $\boldsymbol{E}_{\boldsymbol{A}, \boldsymbol{j}}(\mathbf{k J} / \mathbf{m o l})$ \\
\hline AMOX.1f & $\mathrm{NH}_{3}+\star \rightarrow \mathrm{NH}_{3} \star$ & $k_{\mathrm{AMOX} .1 \mathrm{f}} \cdot p_{\mathrm{NH}_{3}} \cdot\left(1-\theta_{\mathrm{NH}_{3}}\right)$ & $1.2 \times 10^{3}$ & 0 \\
AMOX.1b & $\mathrm{NH}_{3} \star \rightarrow \mathrm{NH}_{3}+\star$ & $k_{\mathrm{AMOX} .1 \mathrm{~b}} \cdot \theta_{\mathrm{NH}_{3}}$ & $1.3 \times 10^{9}$ & 91.0 \\
AMOX.2 & $4 \mathrm{NH}_{3} \star+3 \mathrm{O}_{2} \rightarrow 2 \mathrm{~N}_{2}+6 \mathrm{H}_{2} \mathrm{O}+4 \star$ & $k_{\mathrm{AMOX} .2 \mathrm{f}} \cdot \theta_{\mathrm{NH}_{3}}$ & $2.0 \times 10^{25}$ & 258.8 \\
AMOX.3 & $4 \mathrm{NH}_{3} \star+5 \mathrm{O}_{2} \rightarrow 4 \mathrm{NO}+6 \mathrm{H}_{2} \mathrm{O}+4 \star$ & $k_{\mathrm{AMOX} .3 \mathrm{f}} \cdot \theta_{\mathrm{NH}_{3}}$ & $1.8 \times 10^{29}$ & 302.4 \\
AMOX.4 & $4 \mathrm{NH}_{3} \star+4 \mathrm{NO}+3 \mathrm{O}_{2} \rightarrow 4 \mathrm{~N}_{2} \mathrm{O}+6 \mathrm{H}_{2} \mathrm{O}+4 \star$ & $k_{\mathrm{AMOX} .4 \mathrm{f}} \cdot \theta_{\mathrm{NH}_{3}} \cdot p_{\mathrm{NO}}$ & $4.5 \times 10^{22}$ & 187.8 \\
AMOX.5f & $\mathrm{NO}+1 / 2 \mathrm{O}_{2} \rightarrow \mathrm{NO}_{2}$ & $k_{\mathrm{AMOX} .5 \mathrm{f}} \cdot p_{\mathrm{NO}_{\mathrm{O}}} \cdot p_{\mathrm{O}_{2}}^{1 / 2}$ & $1.2 \times 10^{4}$ & 28.7 \\
AMOX.5b* & $\mathrm{NO}_{2} \rightarrow \mathrm{NO}+1 / 2 \mathrm{O}_{2}$ & $k_{\mathrm{AMOX} .5 \mathrm{~b}} \cdot p_{\mathrm{NO}_{2}}$ & - & - \\
\hline
\end{tabular}

${ }^{*} k_{\mathrm{AMOX} .5 \mathrm{~b}}=\frac{k_{\mathrm{AMOX} .5 \mathrm{f}}}{K_{\text {eq }}}$, equilibrium constant, $K_{\mathrm{eq}}$, calculated from thermodynamic data [29].

Units for $A_{\mathrm{AMOX} .1 \mathrm{~b}}, A_{\mathrm{AMOX} .2}$, and $A_{\mathrm{AMOX.3}}$ are $\mathrm{mol} /\left(\mathrm{s} \cdot \mathrm{kg}_{\mathrm{cat}}\right)$.

Units for $A_{\text {AMOX.1f }}, A_{\mathrm{AMOX} .4}$, and $A_{\mathrm{AMOX} .5 \mathrm{~b}}$ are mol/(s $\left.\cdot \mathrm{kg}_{\mathrm{cat}} \cdot \mathrm{bar}\right)$.

Units for $A_{\text {AMOX.5f }}$ are $\mathrm{mol} /\left(\mathrm{s} \cdot \mathrm{kg}_{\mathrm{cat}} \cdot \mathrm{bar}^{3 / 2}\right)$.

Table 4: Kinetic model for the 3.5 wt. \% Cu-Beta SCR catalyst at 5 vol. $\% \mathrm{H}_{2} \mathrm{O}$ and 10 vol.\% $\mathrm{O}_{2}$.

\begin{tabular}{|c|c|c|c|c|}
\hline Reaction \# & Reaction & Rate Expression $\left(\frac{\mathrm{mol}}{s \cdot \mathrm{kg}_{\mathrm{cat}}}\right)$ & $\boldsymbol{A}_{j}{ }^{d}$ & $E_{A, j}(k J / m o l)$ \\
\hline SCR.1fa & $\mathrm{NH}_{3}+\star \rightarrow \mathrm{NH}_{3} \star$ & $k_{\mathrm{SCR} .1 \mathrm{f}} \cdot \frac{p_{\mathrm{NH}_{3}}}{P_{T}} \cdot\left(1-\theta_{\mathrm{NH}_{3}}\right)$ & $6.68 \times 10^{7} \cdot \rho_{S C R}^{-1}$ & 0 \\
\hline SCR. $1 b^{a}$ & $\mathrm{NH}_{3} \star \rightarrow \mathrm{NH}_{3}+\star$ & $k_{S C R .1 \mathrm{~b}} \cdot \theta_{\mathrm{NH}_{3}}$ & $4.00 \times 10^{15} \cdot \rho_{S C R}^{-1}$ & $145.9 \cdot\left(1-0.97 \cdot \theta_{\mathrm{NH}_{3}}\right)$ \\
\hline SCR.2 & $4 \mathrm{NH}_{3} \star+3 \mathrm{O}_{2} \rightarrow 2 \mathrm{~N}_{2}+6 \mathrm{H}_{2} \mathrm{O}+4$ * & $k_{\mathrm{SCR} .2} \cdot \theta_{\mathrm{NH}_{3}}$ & $9.94 \times 10^{10}$ & 162.87 \\
\hline SCR.3. $f^{b}$ & $\mathrm{NO}+1 / 2 \mathrm{O}_{2} \rightarrow \mathrm{NO}_{2}$ & $k_{\mathrm{SCR} .3 \mathrm{f}} \cdot p_{\mathrm{NO}} \cdot p_{\mathrm{O}_{2}}^{1 / 2}$ & $1.28 \times 10^{3}$ & 31.06 \\
\hline SCR.3b $\mathrm{b}^{b}$ & $\mathrm{NO}_{2} \rightarrow \mathrm{NO}+1 / 2 \mathrm{O}_{2}$ & $k_{\mathrm{SCR} .3 \mathrm{~b}} \cdot p_{\mathrm{NO}_{2}}$ & - & - \\
\hline SCR.4 & $4 \mathrm{NH}_{3} \star+4 \mathrm{NO}+\mathrm{O}_{2} \rightarrow 4 \mathrm{~N}_{2}+6 \mathrm{H}_{2} \mathrm{O}+4 \star$ & $\begin{array}{l}k_{\mathrm{SCR} .4 \mathrm{LT}} \cdot \theta_{\mathrm{NH}_{3}} \cdot p_{\mathrm{NO}} \cdot x_{\mathrm{LT}}+ \\
k_{\mathrm{SCR} .4 \mathrm{HT}} \cdot \theta_{\mathrm{NH}_{3}} \cdot p_{\mathrm{NO}} \cdot x_{\mathrm{HT}}\end{array}$ & $\begin{array}{l}\text { LT: } 1.56 \times 10^{10} \\
\text { HT: } 2.21 \times 10^{8}\end{array}$ & $\begin{array}{l}\text { LT: } 79.67 \\
\text { HT: } 69.38\end{array}$ \\
\hline SCR.5 & $4 \mathrm{NH}_{3} \star+4 \mathrm{NO}+3 \mathrm{O}_{2} \rightarrow 4 \mathrm{~N}_{2} \mathrm{O}+6 \mathrm{H}_{2} \mathrm{O}+4$ * & $\begin{array}{l}k_{\mathrm{SCR} .5 \mathrm{LT} T} \cdot \theta_{\mathrm{NH}_{3}} \cdot p_{\mathrm{NO}} \cdot x_{\mathrm{LT}}+ \\
k_{\mathrm{SCR} .5 \mathrm{HT}} \cdot \theta_{\mathrm{NH}_{3}} \cdot p_{\mathrm{NO}} \cdot x_{\mathrm{HT}}\end{array}$ & $\begin{array}{l}\text { LT: } 6.14 \times 10^{6} \\
\text { HT: } 1.70 \times 10^{4}\end{array}$ & $\begin{array}{l}\text { LT: } 56.22 \\
\text { HT: } 39.88\end{array}$ \\
\hline SCR.6 & $4 \mathrm{NH}_{3} \star+3 \mathrm{NO}_{2} \rightarrow 7 / 2 \mathrm{~N}_{2}+6 \mathrm{H}_{2} \mathrm{O}+4 \star$ & $k_{\mathrm{SCR} .6} \cdot \theta_{\mathrm{NH}_{3}} \cdot p_{\mathrm{NO}_{2}}$ & $1.83 \times 10^{18}$ & 157.17 \\
\hline SCR.7 & $4 \mathrm{NH}_{3} \star+4 \mathrm{NO}_{2} \rightarrow 2 \mathrm{~N}_{2}+2 \mathrm{~N}_{2} \mathrm{O}+6 \mathrm{H}_{2} \mathrm{O}+4 \star$ & $k_{\mathrm{SCR} .7} \cdot \theta_{\mathrm{NH}_{3}} \cdot p_{\mathrm{NO}_{2}}$ & $6.08 \times 10^{16}$ & 140.74 \\
\hline SCR.8 & $4 \mathrm{NH}_{3} \star+2 \mathrm{NO}+2 \mathrm{NO}_{2} \rightarrow 4 \mathrm{~N}_{2}+6 \mathrm{H}_{2} \mathrm{O}+4 \star$ & $k_{\mathrm{SCR} .8} \cdot \theta_{\mathrm{NH}_{3}} \cdot p_{\mathrm{NO}} \cdot p_{\mathrm{NO}_{2}}$ & $8.17 \times 10^{23}$ & 162.21 \\
\hline SCR.9 & $4 \mathrm{NH}_{3} \star+4 \mathrm{NO}_{2} \stackrel{\mathrm{NO}}{\rightarrow} 2 \mathrm{~N}_{2}+2 \mathrm{~N}_{2} \mathrm{O}+6 \mathrm{H}_{2} \mathrm{O}+4 \star$ & $k_{\mathrm{SCR} .9} \cdot \theta_{\mathrm{NH}_{3}} \cdot p_{\mathrm{NO}} \cdot p_{\mathrm{NO}_{2}}$ & $2.65 \times 10^{22}$ & 149.25 \\
\hline SCR. $10^{c}$ & $x_{L T} \rightleftarrows x_{H T}$ & $k_{\text {SCR.10f }} \cdot x_{L T}-k_{\text {SCR.10b }} \cdot x_{H T}$ & - & - \\
\hline
\end{tabular}

${ }^{a}$ Kinetic parameters from [21]. Units of $\mathrm{mol} /\left(\mathrm{s} \cdot \mathrm{m}_{\text {cat }}^{3}\right)$, divided by $\rho_{S C R}$ to convert to mass based value with units of $\mathrm{mol} /\left(\mathrm{s} \cdot \mathrm{kg}_{\text {cat }}\right)$.

${ }^{b} k_{\mathrm{SCR} .3 \mathrm{~b}}=k_{\mathrm{SCR} .3 \mathrm{f}} / K_{\text {eq }}$, equilibrium constant, $K_{\text {eq }}$, calculated from thermodynamic data [29]

${ }^{c} k_{\text {SCR. } 10 \mathrm{~b}} / k_{\text {SCR. } 10 \mathrm{f}}=K_{\text {eq, }, \mathrm{x}}=\exp \left(\frac{-\Delta H-T \Delta S}{R \cdot T}\right), \Delta H=1.04 \times 10^{5} \frac{\mathrm{J}}{\mathrm{mol}}$ and $\Delta S=194.3 \frac{\mathrm{J}}{\mathrm{mol} \cdot \mathrm{K}}$.

${ }^{d}$ Units for $A_{\mathrm{SCR} .1 \mathrm{~b}}$ and $A_{\mathrm{SCR} .2}$ are $\mathrm{mol} /\left(\mathrm{s} \cdot \mathrm{kg}_{\mathrm{cat}}\right)$.

${ }^{d}$ Units for $A_{\mathrm{SCR} .1 \mathrm{f}}, A_{\mathrm{SCR} .3 \mathrm{~b}}, A_{\mathrm{SCR} .4}, A_{\mathrm{SCR} .5}, A_{\mathrm{SCR} .6}$, and $A_{\mathrm{SCR} .7}$, are $\mathrm{mol} /\left(\mathrm{s} \cdot \mathrm{kg}_{\mathrm{cat}} \cdot \mathrm{bar}\right)$.

${ }^{d}$ Units for $A_{\mathrm{SCR} .3 \mathrm{f}}$ are $\mathrm{mol} /\left(\mathrm{s} \cdot \mathrm{kg}_{\mathrm{cat}} \cdot \mathrm{bar}^{3 / 2}\right)$.

${ }^{d}$ Units for $A_{\mathrm{SCR} .8}$ and $A_{\mathrm{SCR} .9}$ are $\mathrm{mol} /\left(\mathrm{s} \cdot \mathrm{kg}_{\mathrm{cat}} \cdot \mathrm{bar}^{2}\right)$. 


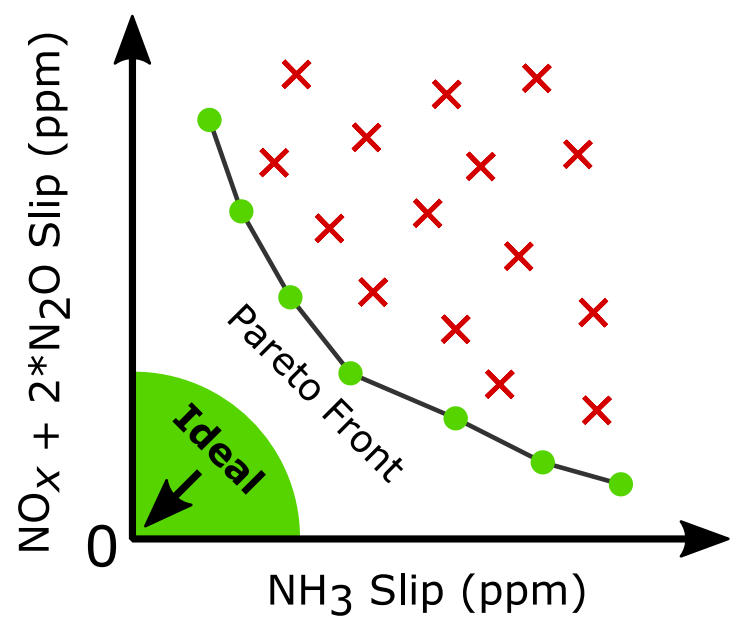

Figure 3: Example of the Pareto front obtained through multi-objective optimization for the ASC system. Ideal solution: origin in green region of graph. Optimal solutions: solid green circles. Non-optimal solutions: red crosses. 


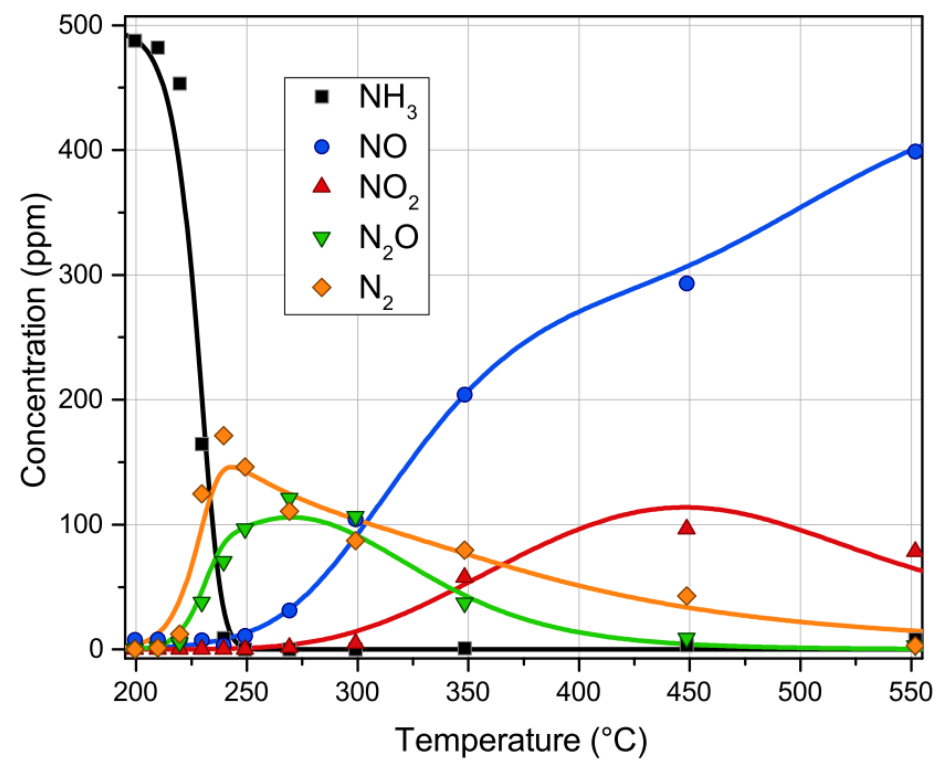

Figure 4: Comparison of the $\mathrm{NH}_{3}, \mathrm{NO}, \mathrm{NO}_{2}, \mathrm{~N}_{2} \mathrm{O}$, and $\mathrm{N}_{2}$ outlet concentrations for the oxidation of $\mathrm{NH}_{3}$ over the 1 wt. \% Pt/TiO 2 catalyst, based on the experimental data (symbols) and the model (solid lines) with the fitted kinetic parameters. Values for $\mathrm{N}_{2}$ were calculated from the $\mathrm{N}$-balance. Operating conditions: $5 \mathrm{mg} 1 \mathrm{wt} \% \mathrm{Pt} / \mathrm{TiO} \mathrm{O}_{2}$ AMOX catalyst sample, $500 \mathrm{ppm} \mathrm{NH}_{3}, 5 \mathrm{vol} \% \mathrm{H}_{2} \mathrm{O}, 10 \mathrm{vol} \% \mathrm{O}_{2}$, and balance $\mathrm{N}_{2}$, with a total flow of 400 $\mathrm{NmL} / \mathrm{min}$. 

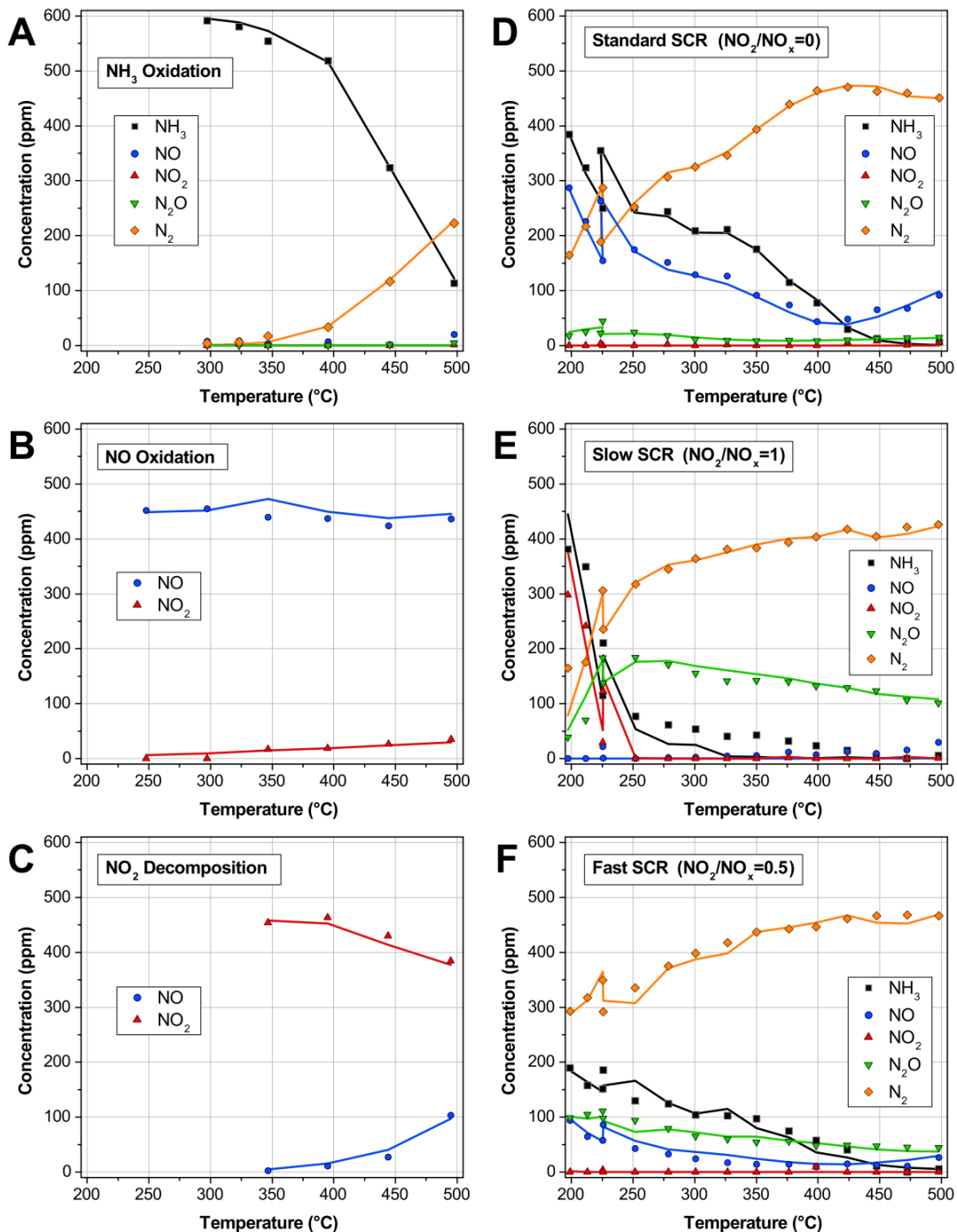

Figure 5: Comparison of $\mathrm{NH}_{3}, \mathrm{NO}, \mathrm{NO}_{2}, \mathrm{~N}_{2} \mathrm{O}$, and $\mathrm{N}_{2}$ outlet concentrations for activity measurements over the $\mathrm{Cu}$-Beta catalyst, based on the experimental data (symbols) and the model fit for A) $\mathrm{NH}_{3}$ oxidation (578 ppm $\mathrm{NH}_{3}$ ), B) NO oxidation (470 ppm NO), C) NO $\mathrm{NO}_{2}$ decomposition (463 ppm NO $\mathrm{N}_{2}$ ), D) standard SCR (563 ppm $\mathrm{NH}_{3}$,

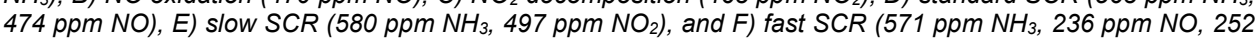
ppm $\mathrm{NO}_{2}$ ). Values for $\mathrm{N}_{2}$ were calculated from the $\mathrm{N}$-balance. Operating conditions: $20 \mathrm{mg}$ of 3.5 wt. $\% \mathrm{Cu}$-Beta SCR catalyst sample, $100 \mathrm{mg} \mathrm{SiC,} 5 \mathrm{vol} . \% \mathrm{H}_{2} \mathrm{O}, 10 \mathrm{vol} . \% \mathrm{O}_{2}$, and balance $\mathrm{N}_{2}$, with a total flow of $1000 \mathrm{NmL} / \mathrm{min}$. Activity measurements for $\leq 225^{\circ} \mathrm{C}$ were made with $40 \mathrm{mg}$ catalyst and $200 \mathrm{mg}$ SiC. This results in two points for $225^{\circ} \mathrm{C}(20 \mathrm{mg}$ and $40 \mathrm{mg}$ catalyst). 


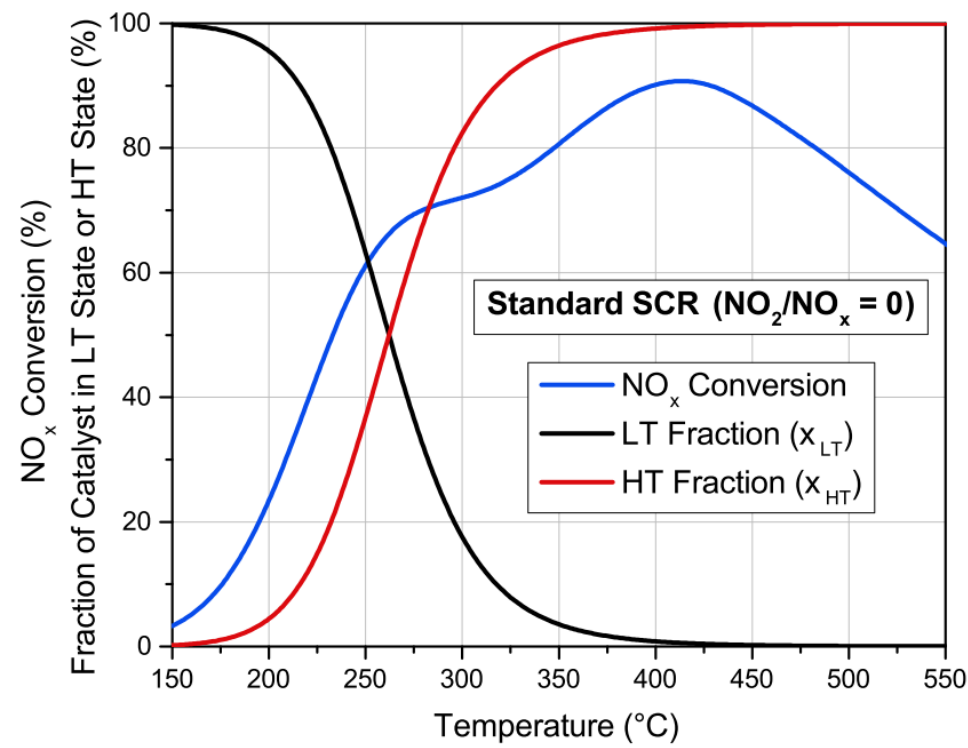

Figure 6: Simulation of the $\mathrm{NO}_{x}$ conversion and the corresponding weighting of $x_{L T}$ and $x_{H T}$ under standard SCR conditions $\left(\mathrm{NO}_{2} / \mathrm{NO}_{x}=0\right)$. Operating conditions: $20 \mathrm{mg}$ of $3.5 \mathrm{wt} \% \mathrm{Cu}$-Beta SCR catalyst sample, $600 \mathrm{ppm} \mathrm{NH}$, $500 \mathrm{ppm} \mathrm{NO}, 5 \mathrm{vol} . \% \mathrm{H}_{2} \mathrm{O}, 10 \mathrm{vol} . \% \mathrm{O}_{2}$, and balance $\mathrm{N}_{2}$, with a total flow of $1000 \mathrm{NmL} / \mathrm{min}$. 
a)
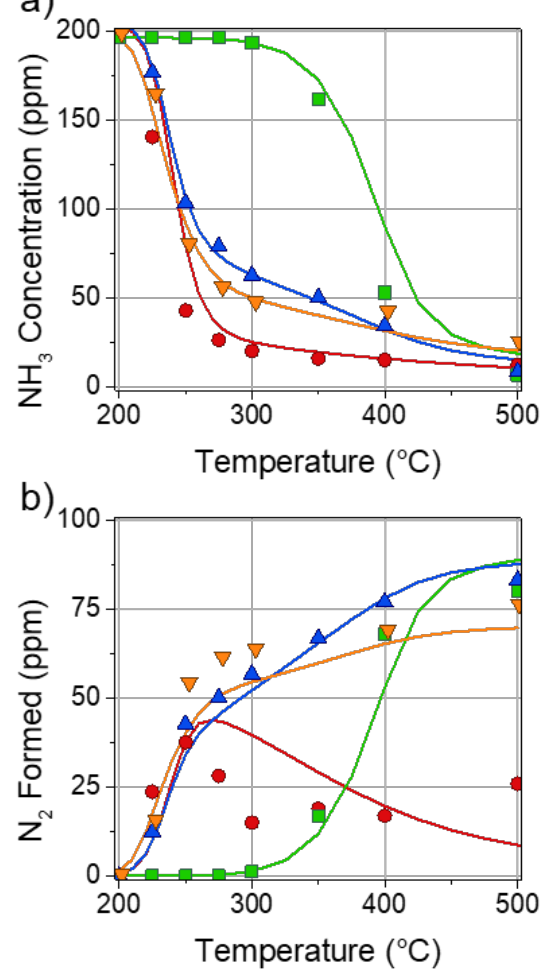

c)

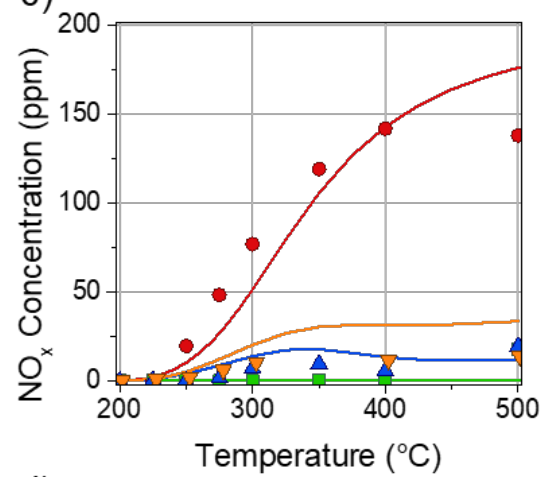

d)

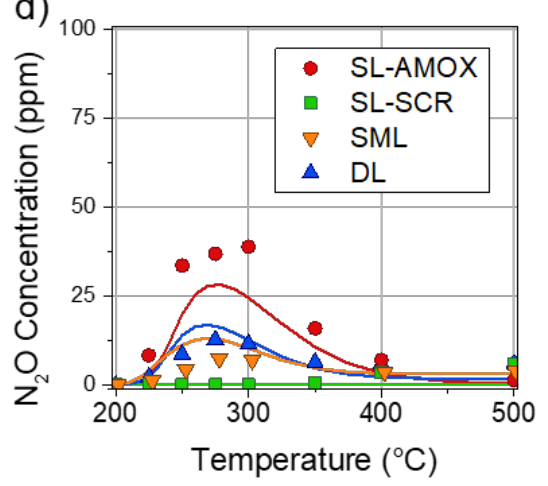

Figure 7: $\mathrm{NH}_{3}$ oxidation over the SL-AMOX, SL-SCR, SML, and DL ammonia slip catalysts. Solid symbols are the outlet concentrations measured during the activity measurements, while the solid lines are the simulated outlet concentrations using the monolith model. Values for $\mathrm{N}_{2}$ were calculated from the $\mathrm{N}$-balance. Operating conditions: $200 \mathrm{ppm} \mathrm{NH}_{3}, 4 \mathrm{vol} \% \% \mathrm{H}_{2} \mathrm{O}, 12 \mathrm{vol} . \% \mathrm{O}_{2}$, and balance $\mathrm{N}_{2}$, with a GHSV of 250,000 hr-1 (total gas flow of $18,200 \mathrm{NL} / \mathrm{hr}$ and monolith volume of $0.073 \mathrm{~L}$ ). 
Table 5: ASC composition, effective diffusivity (expressed as mean pore diameter) and emissions at minimum objective function (eq. 24). Operating conditions: $300^{\circ} \mathrm{C}, 200 \mathrm{ppm} \mathrm{NH}, 4$ vol.\% $\mathrm{H}_{2} \mathrm{O}, 12 \mathrm{vol} . \% \mathrm{O}_{2}$, balance $\mathrm{N}_{2}$, with GHSV 250,000 $\mathrm{hr}^{1}$ (total gas flow of 18,200 NL/hr and monolith volume of $0.073 \mathrm{~L})$. SL-AMOX: single layer AMOX catalyst $\left(\frac{}{A M O X}\right)$; SL-SCR: single layer SCR catalyst $\left(\frac{}{S C R}\right)$; $D L$ : dual layer catalyst $\left(\frac{S C R}{A M O X}\right)$; IDL: inverse dual layer $\left(\frac{A M O X}{S C R}\right) ; H D L-S$ : hybrid dual layer with SCR top layer $\left(\frac{S C R}{A M O X+S C R}\right)$; IHDL-S: inverse hybrid dual layer with SCR bottom $\left(\frac{A M O X+S C R}{S C R}\right)$; HDL-A: hybrid dual layer with $A M O X$ top layer $\left(\frac{A M O X}{A M O X+S C R}\right)$; IHDL-A: inverse hybrid dual layer with AMOX bottom $\left(\frac{A M O X+S C R}{A M O X}\right)$; SML: single mixed layer $\left(\frac{}{A M O X+S C R}\right)$; $D M L:$ dual mixed layer $\left(\frac{A M O X+S C R}{A M O X+S C R}\right)$. Refer to Figure 2 for further details.

\begin{tabular}{|c|c|c|c|c|c|c|c|c|c|c|c|c|c|c|c|c|c|}
\hline \multirow[b]{2}{*}{ Configuration } & \multirow[b]{2}{*}{$\begin{array}{l}\text { Obj. } \\
\text { Func. }\end{array}$} & \multicolumn{5}{|c|}{ Top layer } & \multicolumn{5}{|c|}{ Bottom layer } & \multicolumn{3}{|c|}{ Total } & \multicolumn{3}{|c|}{ Emissions } \\
\hline & & $\begin{array}{c}d_{\text {pore }} \\
\mathrm{nm}\end{array}$ & $\begin{array}{c}\text { AMOX } \\
\text { g/L }\end{array}$ & $\begin{array}{c}\mathrm{Pt} \\
\mathrm{Wt} . \%\end{array}$ & $\begin{array}{c}\mathrm{Pt} \\
\mathrm{mgpt}_{\mathrm{P}} / \mathrm{L}\end{array}$ & $\begin{array}{c}\text { SCR } \\
\mathrm{g} / \mathrm{L}\end{array}$ & $\begin{array}{c}d_{\text {pore }} \\
\mathrm{nm}\end{array}$ & $\begin{array}{c}\text { AMOX } \\
\text { g/L }\end{array}$ & $\begin{array}{c}\mathrm{Pt} \\
\mathrm{Wt} . \%\end{array}$ & $\begin{array}{c}\mathrm{Pt} \\
\mathrm{mgPt} / \mathrm{L}\end{array}$ & $\begin{array}{c}\text { SCR } \\
\text { g/L }\end{array}$ & $\begin{array}{c}A M O X \\
g / L\end{array}$ & $\begin{array}{c}\text { SCR } \\
\text { g/L }\end{array}$ & $\underset{\mathrm{mgt}}{\mathrm{Pt}}$ & $\begin{array}{l}\mathrm{NH}_{3} \\
\mathrm{ppm}\end{array}$ & $\begin{array}{l}\mathrm{NO}_{x} \\
\mathrm{ppm}\end{array}$ & $\begin{array}{l}2^{*} \mathrm{~N}_{2} \mathrm{O} \\
\mathrm{ppm}\end{array}$ \\
\hline DML & 51.4 & 189 & 1.0 & 3.5 & 35 & 16 & 197 & 1.4 & 1.3 & 18 & 177 & \begin{tabular}{|c|}
2.4 \\
\end{tabular} & 193.0 & \begin{tabular}{|c|}
53 \\
\end{tabular} & 16.9 & 14.3 & 20.2 \\
\hline HDL-AMOX & 51.5 & 112 & 1.2 & 2.7 & 32 & & 195 & 1.0 & 2.9 & 29 & 175 & 2.0 & 197.0 & 61 & 16.6 & 14.8 & 20.2 \\
\hline IHDL-SCR & 51.6 & 200 & 1.0 & 6.1 & 61 & 49 & 200 & - & - & - & 140 & 1.0 & 200.0 & 61 & 16.3 & 14.0 & 21.3 \\
\hline & 54.0 & 200 & 1.0 & 6.1 & 61 & - & 200 & - & - & - & 200 & 1.1 & 200.0 & 61 & 12.2 & 16.6 & 25.2 \\
\hline HDL-SCR & 54.8 & 194 & & & & 2 & 200 & 1.0 & 6.1 & 61 & 160 & 1.0 & 162.0 & 61 & 27.3 & .0 & 16.4 \\
\hline SML & 56.3 & - & - & - & - & - & 187 & 3.2 & 1.7 & 54 & 177 & 3.2 & 177.0 & 54 & 30.9 & 10.5 & 15.0 \\
\hline IHDL-AMOX & 59.8 & 163 & 2.0 & 2.7 & 54 & 103 & 38 & 1.0 & 0.3 & 3 & & 3.0 & 103.0 & 57 & 23.8 & 14.8 & 21.1 \\
\hline & 75.2 & 200 & - & - & - & 81 & 200 & 1.0 & 6.0 & 61 & - & 1.3 & 95.0 & 61 & 38.1 & 13.3 & 23.8 \\
\hline SL-AMOX & 119.8 & & - & - & - & & 200 & 1.0 & 6.1 & 61 & & 1.0 & & 61 & 18.7 & 52.5 & 48.6 \\
\hline SL-SCR & 191.5 & - & - & - & - & - & 200 & - & - & - & 200 & - & 200.0 & - & 191.5 & 0.0 & 0.0 \\
\hline
\end{tabular}



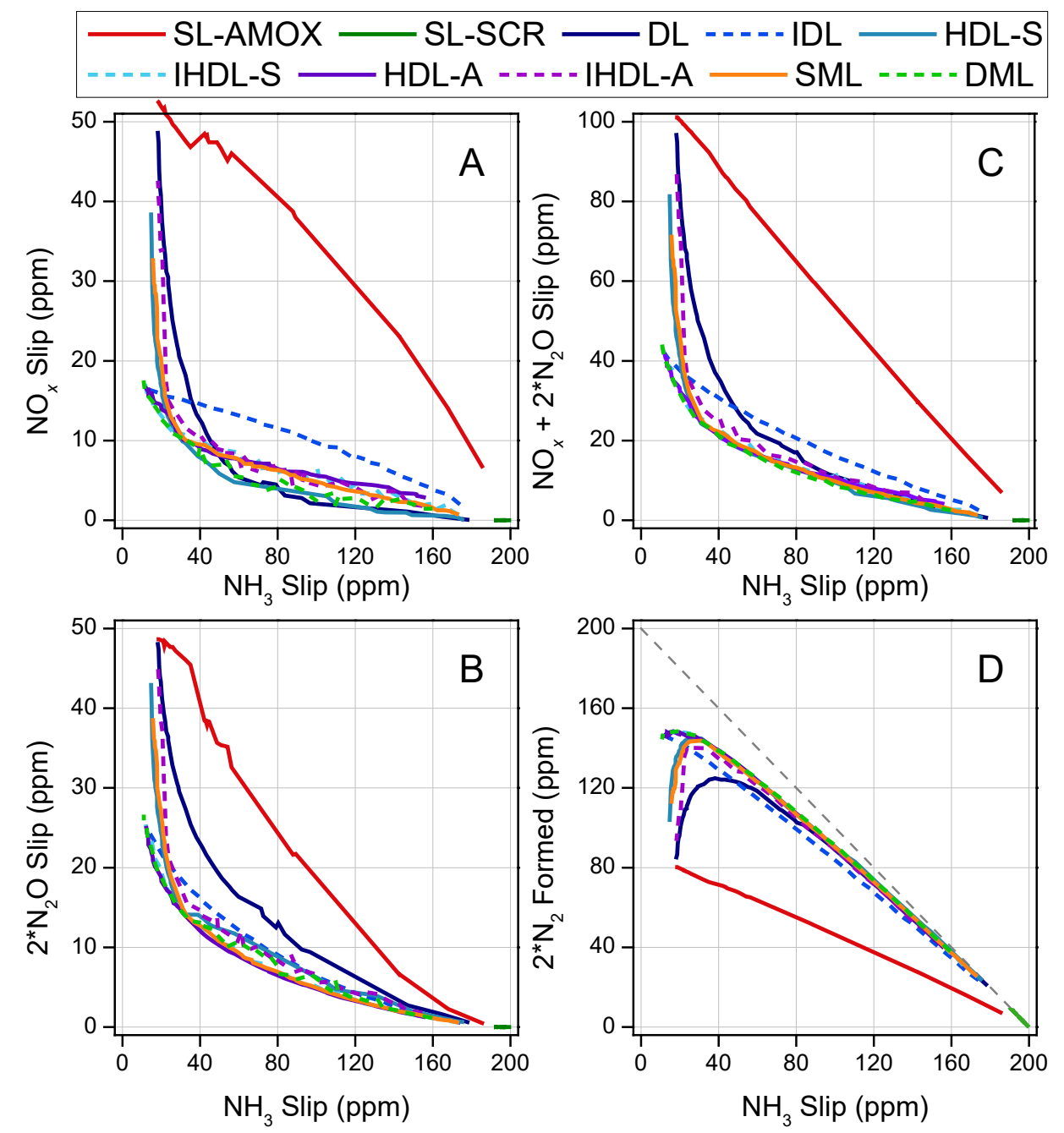

Figure 8: Pareto fronts generated for the ten ammonia slip catalyst configurations investigated. Operating conditions: $300^{\circ} \mathrm{C}, 200 \mathrm{ppm} \mathrm{NH}_{3}, 4$ vol.\% $\mathrm{H}_{2} \mathrm{O}, 12$ vol.\% O $\mathrm{O}_{2}$, balance $\mathrm{N}_{2}$, with GHSV 250,000 hr ${ }^{-1}$ (total gas flow of $18,200 \mathrm{NL} / \mathrm{hr}$ and monolith volume of $0.073 \mathrm{~L})$. SL-AMOX: single layer AMOX catalyst $\left(\frac{}{\text { AMOX }}\right)$; SL-SCR: single layer SCR catalyst $\left(\frac{}{S C R}\right)$; DL: dual layer catalyst $\left(\frac{S C R}{A M O X}\right)$; IDL: inverse dual layer $\left(\frac{A M O X}{S C R}\right)$; HDL-S: hybrid dual layer with SCR top layer $\left(\frac{S C R}{A M O X+S C R}\right)$; IHDL-S: inverse hybrid dual layer with SCR bottom $\left(\frac{A M O X+S C R}{S C R}\right)$; HDL-A: hybrid dual layer with $A M O X$ top layer $\left(\frac{A M O X}{A M O X+S C R}\right)$; IHDL-A: inverse hybrid dual layer with AMOX bottom $\left(\frac{A M O X+S C R}{A M O X}\right)$; SML: single mixed layer $\left(\frac{}{A M O X+S C R}\right) ; D M L:$ dual mixed layer $\left(\frac{A M O X+S C R}{A M O X+S C R}\right)$. Refer to Figure 2 for further details. 


\section{Supporting Information}

The performed multi-objective optimization will now be described in more detail. As illustrated by the figure below, the process begins with a set of initial guesses, either randomly adhering to selected constraints, or based on user defined inputs. The parameter set consists of 50 initial guesses multiplied by the number of parameters $\left(n_{\text {param }}\right)$ being varied, to account for the increase in possible solutions with the increase in parameters for the more complex configurations. The genetic algorithm generates a new collection of parameter values based on a score of according to the objective function (eq. 24). Generally, the best performing parameter sets are selected as initial guesses for the next iteration, but some poorer performing parameter sets may also be selected to diversify the optimization. The generated parameter sets may be either: 1) elite, which are replicates of the most fit parameter sets, 2) mutation, which are created by introducing random changes to a single parameter set, and 3) crossover, which are created by combining the vectors of a pair of initial guesses. Through the successive iterations, the parameter sets evolve toward a set of optimal solutions. This loop of the algorithm is repeated until a stopping criteria is met, such as when a maximum number of iterations is reached or when the relative change in the objective function decreases below a set tolerance. In this study a maximum number of 10 iterations $\left(n_{\text {gen }}\right)$ was used as the stopping criteria. The total number of simulations performed for a configuration is therefore $50 \times n_{\text {param }} \times n_{\text {gen }}$, including the replicates from previous generations. The Pareto fronts resulting from the final set of optimal solutions were used to evaluate the sensitivity of the ASC performance to the possible ASC configurations.

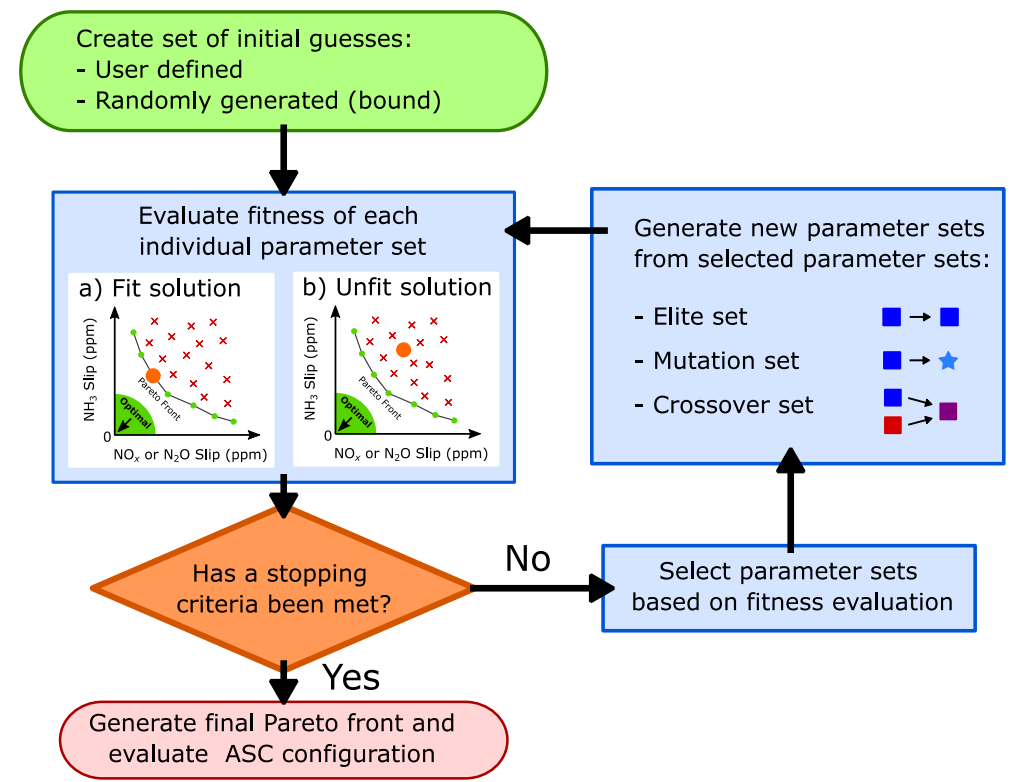

Figure 9: Flow chart for the genetic algorithm used to optimize the multi-objective ammonia slip catalyst design. 